\title{
ENTRE SOLIDARIDAD Y REALPOLITK. LA SOCIALDEMOCRACIA ALEMANA Y EL SOCIALISMO PORTUGUÉS DE LA DICTADURA A LA DEMOCRACIA
}

\author{
Antonio Muñoz Sánchez \\ Instituto de Ciêncías Sociais, Universidade de Lisboa \\ antonio.munoz@ics.ulisboa.pt
}

Recibido: 06/01/2016 - Aceptado: 08/09/2016

Cómo citar este artículo/Citation:

Antonio MUÑOZ SÁNCHEZ (2017), “Entre solidaridad y realpolitik. La socialdemocracia alemana y el socialismo portugués de la dictadura a la democracia", Hispania Nova, 15, págs. 243-273.

DOI: https://doi.org/10.20318/hn.2017.3488

\section{Between solidarity and realpolitik. German social democracy and Portuguese socialism from dictatorship to democracy}

Copyright: (c) HISPANIA NOVA es una revista debidamente registrada, con ISSN 1138-7319 y Depósito Legal M 9472-1998. Los textos publicados en esta revista están -si no se indica lo contrario- bajo una licencia Reconocimiento-Sin obras derivadas 3.0 España de Creative Commons. Puede copiarlos, distribuirlos y comunicarlos públicamente siempre que cite su autor y la revista y la institución que los publica y no haga con ellos obras derivadas. La licencia completa se puede consultar en: http://creativecommons.org/licenses/by-nd/3.0/es/deed.es
Resumen: El artículo analiza las relaciones de la socialdemocracia alemana con el socialismo luso en el contexto de la política de la RFA hacia Portugal. La primera parte se ocupa de los últimos años del Estado Novo. Muestra cómo al entrar en el gobierno en 1966, el SPD no introdujo cambios en la tradicional política alemana de amistad con la dictadura de Salazar, lo que le llevó a poner sus relaciones con la oposición lusa en un segundo plano. Pese a ello, la Fundación Ebert abrió un canal informal de apoyo al pequeño grupo de activistas en torno a Mario Soares que fue crucial para su consolidación y conversión en partido en 1973. La segunda parte se centra en la Revolución de los Claveles que siguió al colapso de la dictadura en abril de 1974. Expone como el gobierno de Helmut Schmidt percibió la radicalización del proceso democratizador portugués con enorme aprensión y decidió apoyar de manera masiva al Partido Socialista en la esperanza de que pudiera hacer de contrapeso al poderoso Partido Comunista. Trata además de demostrar que este respaldo alemán contribuyó de manera decisiva a fortalecer al Partido Socialista, que finalmente saldría como el gran vencedor de la Revolución y lideraría el establecimiento de una democracia de tipo occidental.

Palabras clave: Portugal, RFA, socialismo, Estado Novo, Revolución de los Claveles, transición democrática
Abstract: The essay analyzes the relations of the German social democracy with the Portuguese socialism in the context of the West German policy towards Portugal. The first part focuses on the last years of the Estado Novo It shows how after entering the government in 1966 the SPD did not introduce any major change in the traditional German policy of good relations with the Portuguese dictatorship. The slight contacts of the German social democracy with the opposition movement were mostly channeled through the Friedrich Ebert Foundation. Its support though came to be instrumental for the tiny group of socialists around Mario Soares, which in 1973 decided to found a party. The second part concentrates on the Carnation Revolution that followed the collapse of the dictatorship in April 1974. It explains how the fear of a political radicalization in Portugal led the Government of Helmut Schmidt to massively support the Socialist Party, trying to counterbalance the powerful Communist Party. Lastly it tries to demonstrate that this external support was essential to strengthen the socialists, which eventually prevailed over the communists in the Revolution and turned into the leading force in the establishing of a western democracy.

Keywords: Portugal, FRG, socialism, dictatorship, Estado Novo, carnation Revolution, transition to democracy. 


\section{ENTRE SOLIDARIDAD Y REALPOLITIK. LA SOCIALDEMOCRACIA ALEMANA Y EL SOCIALISMO PORTUGUÉS DE LA DICTADURA A LA DEMOCRACIA}

\section{LA RFA Y EL ESTADO NOVO: UNA AMISTAD AL CALOR DE LA GUERRA FRÍA}

A finales de la década de los cincuenta del siglo pasado, el Portugal de Antonio de Oliveira Salazar era consciente de que no iba a poder contar con el respaldo de EEUU para defender su Imperio y comenzó a buscar otros apoyos dentro de la OTAN. A su vez, la RFA de Konrad Adenauer, temiendo ser ocupada por tropas de soviéticas en una eventual guerra entre los bloques, deseaba establecer una base logística en el sur de Europa donde replegar parte de sus tropas. Esta confluencia de intereses geoestratégicos entre Lisboa y Bonn llevó a la firma en 1960 de diversos acuerdos bilaterales que preveían la instalación de una base militar alemana en Beja y la venta a Portugal de material de guerra. Como contraprestación a una relación muy beneficiosa para la RFA, Portugal recibiría ayuda financiera y técnica para modernizar sus infraestructuras. La cooperación impulsada a nivel oficial iba a abrir además las puertas a las inversiones privadas alemanas en Portugal, atraídas por los bajos impuestos, la estabilidad del escudo y la mano de obra más barata de Europa. De esta forma, en el plazo de muy pocos años la RFA se convirtió en un aliado estratégico de la dictadura portuguesa. ${ }^{1}$

Admiradores sinceros de Salazar, los dirigentes conservadores de la joven RFA nunca ocultaron su simpatía con el Estado Novo, un sistema para ellos legítimo además de socio fiel en la lucha contra el comunismo. ${ }^{2}$ Sin temor a las críticas de la opinión pública alemana, con diferencia la más anticomunista de la Europa democrática, la única preocupación del gobierno de Bonn por su amistad con Lisboa era el daño que pudiera causar al prestigio internacional de la RFA, lo cual le obligó a llevar sus negocios bélicos con extrema cautela. ${ }^{3}$ Pero a medida que la guerra en las colonias se fue enconando, mantener el secreto se hizo imposible y las jóvenes naciones africanas apuntaron acusadoramente a la RFA como cooperador en los crímenes del Ejército portugués.

Para acabar con esta incómoda situación, la Gran Coalición formada en diciembre de 1966 se planteó reducir drásticamente la venta de armas y cerrar la base de Beja. Contra esta opción se posicionaron sin embargo algunos ministros que, siguiendo el argumento del embajador en Lisboa, Herbert Müller-Roschach, entendían que la decisión "destrozaría el núcleo mismo de nuestras

\footnotetext{
${ }^{1}$ Mónica FONSECA, A Força das Armas: o Apoio da República Federal da Alemanha ao Estado Novo (1958-1968), Lisboa, Ministério dos Negócios Estrangeiros, 2007.

2 Jürger ZIMMERER, “'Der bestregierte Staat Europas': Salazar und das Neue Portugal im konservativen AbenlandDiskurs der frühen Bundesrepublik Deutschland”, en: Portugal-Alemanha-Brasil, Actas do VI Encontro LusoAlemão, Braga, Universidade do Minho, 2003, pp. 81-101.

${ }^{3}$ Mónica FONSECA, A Força das Armas, p. 170.
} 
relaciones" con Portugal, dejando muy tocada la cooperación económica. ${ }^{4}$ Una cooperación que podía experimentar un extraordinario impulso si Bonn aceptaba la invitación de Lisboa para que empresas alemanas participasen en la construcción de una gigantesca presa en Mozambique. Ante esta disyuntiva, la RFA eligió mantener la colaboración militar, aunque redujo la venta de armas y redimensionó el proyecto de Beja para dejarlo en un simple aeropuerto de prácticas. La defensa de los entretanto crecidos intereses alemanes en Portugal merecía, en fin, continuar cultivando una amistad con los dirigentes lusos que, según el embajador, era "vista con envidia en los círculos diplomáticos de Lisboa". $^{5}$

Guardianes fieles de esas relaciones privilegiadas con el Estado Novo eran diplomáticos ultraconservadores como el propio Müller-Roschach, quien sería retirado de la embajada de Lisboa en 1968 al trascender a la opinión pública que, como alto funcionario del Auswärtiges Amt (Ministerio de Asuntos Exteriores) durante la guerra mundial, había trabajado en la organización del Holocausto. ${ }^{6}$ Devoto de Salazar, el embajador consideraba a Portugal un oasis de paz y armonía cuyo único problema era el carácter mortal de su extraordinario líder. Esta sagaz observación llevaba a Müller-Roschach a concluir a la altura de 1966 que era necesario prepararse para el día en que el primer ministro faltara, reconociendo con cierta desgana la necesidad de acercarse al mundo para él ignoto de los demócratas lusos. Si Salazar, gracias a su "conocimiento del alma del pueblo portugués, (...) de sus cualidades y sobre todo de sus debilidades", había conseguido anular a la oposición durante casi cuarenta años, ahora los tiempos estaban cambiando y la RFA debía acompasarse. ${ }^{7}$ En este sentido, resultaba prioritario acabar con la pésima imagen que los demócratas tenían de la República de Bonn debido a su incondicional apoyo al Estado Novo, pues podía influir negativamente en las relaciones bilaterales durante la transición que tarde o temprano llegaría. ${ }^{8}$ Era pues el momento de introducir algún tipo de apoyo al movimiento democrático luso, lo que abría un amplio campo de acción a los partidos alemanes y muy especialmente al socialdemócrata.

\section{LOS PRIMEROS CONTACTOS CON EL SOCIALISMO PORTUGUÉS}

Para el SPD el antisalazarismo fue terra incognita hasta septiembre de 1966, cuando el secretario general de Acción Socialista Portuguesa (ASP), Mario Soares, y el secretario de relaciones internacionales, Francisco Ramos da Costa, Ilamaron a la puerta de su sede central en Bonn y propusieron a un funcionario del departamento de relaciones internacionales el establecimiento de relaciones fraternales. ${ }^{9}$ Semanas más tarde, y sin que mediara indicación del SPD, inmerso en las negociaciones para la formación de la Gran Coalición, se iba a producir también el primer contacto de

\footnotetext{
${ }^{4}$ Akten zur Auswärtigen Politik der Bundesrepublik Deutschland, 1967, documento 295.

${ }^{5}$ Informe anual 1967 de la embajada alemana en Portugal, Politisches Archiv - Auswärtiges Amt (PAAA), Berlin, B26/408.

${ }^{6}$ Eckart CONZE, Norbert FREI, Peter HAYES, Moshe ZIMMERMANN, Das Amt und die Vergangenheit. Deutsche Diplomaten im Dritten Reich und in der Bundesrepublik, Múnich, Pantheon, 2012, pp. 665 y ss.

${ }^{7}$ Informe anual 1966 de la embajada alemana en Portugal, 3.4.1967, PAAA, B26/410.

${ }^{8}$ Informe del embajador Müller-Roschach, 25.1.1967, PAAA, B26/410.

9 Francisco Ramos da Costa a Hans-Eberhard Dingels, 31.12.1966, Arquivo da Fundação Mario Soares (AFMS), Lisboa, DRC 04283.001.
} 
su cercana Fundación Friedrich Ebert con la ASP. La iniciativa partió de Robert F. Lamberg, durante una misión a Madrid para fomentar la cooperación con el grupo de Enrique Tierno Galván. Animado por Raul Morodo, el emisario de la Fundación Ebert viajó a Lisboa en el mes de noviembre de 1966 y de regreso a Bonn redactó un amplio informe que puede considerarse el primer acercamiento de la socialdemocracia alemana a la realidad de la oposición socialista al Estado Novo. ${ }^{10}$

Procedente de España, donde se palpaba el dinamismo de una sociedad que estaba forzando a la dictadura franquista a liberalizarse, Robert Lamberg quedó sorprendido por el atraso económico, la falta de pulso social y la esclerosis política de Portugal. El país parecía una isla anclada en el tiempo, con escasas señales de modernización y situaciones de pobreza propias del siglo XIX. En cuanto al bizarro régimen del doctor Salazar, uno de los rasgos más característicos era su asombrosa capacidad desmovilizadora, habiendo la población interiorizado el miedo y el terror como algo natural. No existía nada parecido a un debate público, y los diarios eran panfletos con menor valor informativo y veracidad que los "órganos soviéticos en tiempos de Stalin". La sucesión del anciano dictador constituía un tema tabú y el único mensaje político repetido hasta la saciedad por el régimen era un apres nous le déluge. Dado el absoluto hermetismo del Estado Novo, cualquier previsión de futuro era pura especulación. En todo caso, resultaba evidente que la oposición iba a ganar en relevancia. Así lo entendían las embajadas de los principales países europeos, que habían abierto canales de comunicación con ella. La legación alemana constituía aquí una excepción, lo cual alimentaba la pésima reputación de la RFA en estos círculos democráticos. Pese a la condescendencia de Occidente con la dictadura y pese a su machacona propaganda anticomunista, el prestigio del bloque del Este entre la oposición no comunista portuguesa era "igual a cero" y existía una abierta voluntad de cooperación con los partidos europeos.

Robert Lamberg conoció en Lisboa a Mario Soares, Gustavo Soromenho, Raul Rego y otros miembros de ASP. Todos ellos intelectuales y hommes d'affaires que en su tiempo libre conspiraban contra la dictadura, concebían documentos que elevaban a las autoridades e intentaban proyectar al exterior a través de los escasos corresponsales de prensa en Lisboa. La aspiración de estos voluntariosos activistas era ganar adeptos, infiltrase en los sindicatos corporativos e ir ampliando su influencia con la vista puesta en la creación de un partido que pudiera ocupar un papel relevante en la política portuguesa tras la dictadura. Carentes de recursos, los socialistas eran muy dependientes de la ayuda externa, que de momento llegaba con cuentagotas. Como conclusión, Lamberg animaba al conjunto de la socialdemocracia alemana a apoyar por todos los medios a la ASP. Y ello no solo por solidaridad con unos compañeros necesitados, sino como parte de una política alemana dirigida a promover activamente la democracia en la península ibérica: "Acción posee un considerable potencial de crecimiento en el conjunto de la oposición democrática de Portugal. Políticamente es nuestro partenaire natural. Nuestra ayuda sería de gran importancia para la configuración del futuro Portugal. Además podría en cierto modo neutralizar o eliminar las consecuencias perjudiciales para la RFA de la, en mi opinión, política miope del Auswärtiges Amt". ${ }^{11}$

Pocos días después de recibir de la Fundación Ebert este informe, Willy Brandt prometió su cargo como ministro de Exteriores de la Gran Coalición. El presidente del SPD tuvo así en su mano

\footnotetext{
${ }^{10}$ Testimonio de Robert Lamberg, febrero de 2013, Buenos Aires. Archivo personal del autor.

${ }^{11}$ Informe de Lamberg sobre su viaje a Portugal, noviembre 1966, Archiv der sozialen Demokratie (AdsD), Bonn, Willy Brandt Archiv (WBA), 1/5.
} 
otorgar a la recién descubierta ASP un espacio en la política de la RFA hacia Portugal. Pero en contra del consejo de Lamberg y también del embajador Müller-Roschach, el ministro no lo consideró oportuno. Las relaciones bilaterales, que ya sufrían tensiones a causa de la decisión de Bonn de reducir la venta de armas y devaluar la base de Beja, no debían complicarse aún más otorgando a un ínfimo grupo opositor un apoyo visible que molestaría profundamente a las irascibles autoridades de Lisboa. Por paradójico que nos pueda parecer retrospectivamente, con su actitud Willy Brandt no creía estar actuando contra los intereses de los socialistas lusos. Imbuidos en las teorías modernizadoras tan en boga en los años sesenta, los líderes socialdemócratas alemanes entendían que, al igual que España aunque a ritmo más lento, Portugal caminaba inevitablemente hacia la democracia empujada por el crecimiento económico y su cada vez más intensa relación con Europa. ${ }^{12}$ Esta certeza les hacía creer que estrechar los lazos con el Estado Novo era también rendir un servicio a la futura libertad de Portugal, limpiando así la mala conciencia que pudiera provocarles su intimidad con un régimen más próximo al fascismo que a la democracia que ellos querían atisbar en el horizonte. En todo caso, los dirigentes del SPD consideraban que el protagonismo de la futura transición no lo iba a tener la débil oposición sino los sectores moderados del régimen interesados en dar una salida política a la guerra de África y en orientar a Portugal hacia Europa. Si bien esos grupos evolucionistas se movían de momento en la sombra, ya estarían tomando posiciones para el momento decisivo de la sucesión del anciano Salazar. ${ }^{13}$

La llegada del SPD al gobierno no constituyó por tanto un revulsivo para sus recién estrenadas relaciones con la ASP, sino más bien todo lo contrario. La primera iniciativa de apoyo del partido de Willy Brandt a la ASP no llegaría hasta la primavera de 1968, y no sería de motu proprio sino en respuesta al pedido de la Internacional Socialista a sus partidos miembros para que protestaran ante el gobierno de Lisboa por la deportación de Mario Soares a la isla de Santo Tomé. ${ }^{14}$ El vicepresidente del SPD Alfred Nau dirigió entonces una nota al embajador portugués en Bonn, Manuel Homem de Melo, en la que, dejando clara su voluntad de no inmiscuirse en asuntos internos de su país, "con el que la RFA mantiene buenas relaciones", pedía que se aliviase la situación personal de Mario Soares. ${ }^{15} \mathrm{El}$ casi total desapego mostrado por el SPD hacia el ASP desde su primer contacto en septiembre de 1966, unido a las especulaciones de la prensa internacional sobre una posible visita del ministro de Exteriores alemán a Lisboa ${ }^{16}$, produjeron perplejidad y malestar entre los socialistas portugueses, y así se lo haría saber sin tapujos Francisco Ramos da Costa a Willy Brandt en el cálido verano de 1968:

${ }^{12}$ Antonio MUÑOZ SÁNCHEZ, El amigo alemán. El SPD y el PSOE de la dictadura a la democracia, Barcelona, RBA, 2012.

13 “Lucha por la sucesión de Salazar en Portugal”, SPD Pressedienst, 19.10.1967.

${ }^{14}$ Hans-Eberhard Dingels a Alfred Nau, 18.4.1968, AdsD, SPD Parteivorstand 10523.

${ }^{15}$ Alfred Nau a Manuel Homem de Melo, 26.4.1968, AdsD, SPD Parteivorstand 10523.

${ }^{16}$ Durante una reunión del Consejo Atlántico celebrada en Bruselas en diciembre de 1967, Alberto Franco Nogueira invitó a Willy Brandt a visitar oficialmente Portugal. Días más tarde, se anunció que el ministro de Exteriores de la RFA visitaría España en 1968, lo que Franco Nogueira aprovechó para reiterar su invitación. Las noticias sobre un posible viaje de Brandt a Madrid y Lisboa despertó las críticas de los socialistas ibéricos y alemanes, que contribuyeron a la cancelación de la iniciativa. Embajador Müller-Roschach a Willy Brandt informando de su conversación con Franco Nogueira, 27.12.1967, PAAA, B26/409; Manuel Tito de Morais y Francisco Ramos da Costa a Willy Brandt protestando ("Nous nos demandons comment la diplomatie allemand, sous la direction d'un camarade à nous, democrate socialiste comme nous meme, a pu donner son accord a ce 
Jusqu'à maintenant votre parti s'est montre indifférent aux approches que I'ASP lui a fait pour établir des relations amicales comme partis frères socialistes, quoique vous n'ignorez pas l'accueil et l'aide qui nous ont été donnés par l'International Socialiste et, individuellement, d'autres partis socialistes, même ceux qui partagent les responsabilités du pouvoir (...). Moi même, a plusieurs reprises, j'ai profité de l'invitation a differents congres socialistes (...). Je ne vous fait pas l'injustice de croire que vous admettiez que le fascisme salazarien va durer encore longtemps et vos services d'information vous ont renseigné certainement que notre organisation démocrate et socialiste (ASP) avec les catholiques de gauche font le bloc le plus fort et décisif de l'Opposition Démocratique Portugaise (...) L'ASP jouera un rôle important dans une alternative d'emergence au fascisme et nous serions appelles a trouver une solution a la guerre coloniale en Guinée, Angola et Mozambique; a ce but nous avons formulé une politique de decolonisation. ${ }^{17}$

Mientras tanto, y contando con el beneplácito del propio presidente del SPD, la Fundación Friedrich Ebert mostró desde el citado viaje de Robert Lamberg a Lisboa una abierta disposición a colaborar con la ASP. En la primavera de 1967, el Auswärtiges Amt otorgó a la Fundación Ebert fondos para crear una línea de becas a estudiantes portugueses y para financiar una visita a Bonn de Mario Soares y varios de sus camaradas con el objetivo de conocerse y debatir con ellos medidas concretas de cooperación. ${ }^{18}$ Este viaje tendría sin embargo que ser cancelado debido al encarcelamiento y deportación de Soares. En cuanto a las becas, de momento los compañeros lusos no propusieron ningún candidato. La primera medida de apoyo se concretaría en julio de 1967 mediante la participación de dos estudiantes de Lisboa en un seminario organizado cerca de Colonia para socialistas españoles. ${ }^{19}$ Por humilde que fuera este comienzo, la semilla del proyecto de la Fundación Ebert en Portugal ya estaba puesta, y a partir de entonces no dejaría de desarrollarse.

La posición de la socialdemocracia alemana hacia el socialismo portugués aquí pergeñada para el periodo de 1966 a 1968 apenas experimentará cambios de fondo en los años siguientes, como veremos a continuación. Por un lado, encontraremos un SPD muy poco inclinado a dar satisfacción a las peticiones de respaldo político formuladas por la ASP debido a la prioridad que para el partido de gobierno en Bonn tenía la buena relación con las autoridades de Lisboa, y que en todo caso se mostrará dispuesto a echar puntualmente una mano a los compañeros mediante una intermediación a través de cauces diplomáticos. Por otro, comprobaremos como la Fundación Ebert desplegará una amplia serie de iniciativas dirigidas a respaldar los esfuerzos de la ASP por consolidarse como organización en Portugal y por proyectarse en los círculos socialistas europeos.

\section{CONFIANDO EN LA REFORMA IMPOSIBLE. WILLY BRANDT Y EL MARCELISMO}

En septiembre de 1968, Marcelo Caetano sucedió al enfermo Antonio de Oliveira Salazar como primer ministro. El cambio de guardia en Lisboa coincidió con los preparativos de la visita oficial a Portugal del canciller alemán Kurt-Georg Kiesinger, pensada para reafirmar una relación bilateral algo

malheureus project"), abril 1968, AdsD, SPD Parteivorstand 10523; Hans-Eberhard Dingels al secretario general del PSOE Rodolfo Llopis anunciando la anulación de la visita, 11.4.1968, AdsD, SPD Parteivorstand 10513.

${ }^{17}$ Francisco Ramos da Costa a Willy Brandt, 25.6.1968, AdsD, SPD Parteivorstand 10513.

${ }^{18}$ Günter Grunwald al Auswärtiges Amt, 12.4.1967, AdsD, FES Hausakten 1373.

${ }^{19}$ Entre los participantes españoles estaba el futuro ministro Pedro Solbes. Informe sobre el seminario, celebrado en la escuela de formación de Bergneustadt entre el 3 y el 15 de julio de 1967, AdsD, FES Hausakten 1374. 
tocada por la decisión de la Gran Coalición de reducir la cooperación militar. Ante el riesgo de que la sucesión de Salazar trajese una situación de inestabilidad, el gobierno de Bonn pensó en anular la visita, pero descartó esta opción enseguida al constatar que la transición discurría tranquila y, para desaliento de la oposición, ante la absoluta indiferencia de la población. ${ }^{20}$ El viaje del canciller a Portugal, el único realizado por un jefe de gobierno europeo durante el Estado Novo, provocó algunas críticas en la RFA, donde las revueltas estudiantiles estaban sacudiendo las conciencias de una sociedad que ahora se preguntaba por el sentido de la amistad de su gobierno con las dictaduras del sur de Europa. Al tiempo que garantizó a Caetano la continuidad de las excelentes relaciones, el canciller declaró que para la RFA el colonialismo estaba superado. Con estos mensajes contradictorios, Kiesinger dejó Portugal convencido de que los vientos de cambio habían penetrado en el país ibérico. ${ }^{21}$

El relevo en la cúspide del Estado Novo se produjo en un momento en que Occidente comenzaba a albergar una seria preocupación por la guerra en Angola, Mozambique y Guinea Bissau. Si el Ejercito luso había logrado mantener la iniciativa militar en aquellos territorios, ello se debía menos al arrojo de sus soldados que al hecho de que hasta entonces los países comunistas se hubiesen mantenido al margen y no hubiesen armado a los movimientos de liberación. Visto el creciente interés de la Unión Soviética y de China por el Tercer Mundo, tal situación podía cambiar y las colonias portuguesas corrían el riesgo de convertirse en nuevos Vietnam, con consecuencias imprevisibles para el statu quo mundial. Los aliados de la OTAN recibieron por tanto con gran expectación a Caetano, quien parecía dispuesto a marcar el camino de salida del laberinto africano en el que su país llevaba años extraviado. En mayor o menor grado, todos ellos se mostraron dispuestos a otorgar al nuevo líder portugués el tiempo y la comprensión que reclamaba para llevar adelante su proyecto, nunca explicitado, de descolonización. En el gobierno de Bonn, Caetano encontrará además un fuerte apoyo a su intención de modernizar la economía y aproximar Portugal a la CEE. ${ }^{22}$

La primavera marcelista despertó grandes esperanzas entre los demócratas portugueses, pero no así en el gobierno de Bonn. A alimentar este escepticismo contribuyó el nuevo embajador en Lisboa, el ex miembro de las SS Hans Schmidt-Horix, quien se suicidaría en 1971. Desde muy pronto, el embajador llamó la atención sobre la fragilidad del proyecto aperturista de Caetano, debido al fuerte rechazo que encontraba en el poderoso sector conservador y africanista. La liberalización del Estado Novo y la descolonización sólo podían entenderse por tanto como procesos lentos, sinuosos y siempre amenazados por un golpe involucionista. Aquella no era desde luego la hora feliz de los demócratas, como por ejemplo los socialistas del liberado Mario Soares querían creer. En todo caso, sí podía ser el momento de los sectores reformistas y europeístas del régimen a los que Caetano intentaba promover. ${ }^{23}$ La oposición democrática apenas era un tierno brote que medraba al calor de la liberalización. Así se habría puesto de manifiesto, según Schmidt-Horix, en el Congreso Republicano de

\footnotetext{
${ }^{20}$ Nota del Auswärtiges Amt sobre el viaje, 30.9.1968, PAAA, B26/409.

${ }^{21}$ Informe sobre la visita del canciller Kiesinger a España y Portugal del 24 al 30 de octubre de 1968, 8.11.1968, $P A A A$, B26/409; protocolo de la conversación con Franco Nogueira, octubre de 1968, Archiv für ChristlichDemokratische Politik, Sankt Augustin, NL Kurt Georg Kiesinger, I-226-A289.

22 Para un profundo análisis de las relaciones bilaterales durante el marcelismo, véase Rui LOPES, West Germany and the Portuguese Dictatorship, 1968-1974, Londres, Palgrave, 2014.

${ }^{23}$ Informe de la embajada sobre la reestructuración de União Nacional, 1.7.1969, PAAA, B26/399.
} 
Aveiro en mayo de 1969. Más que por su importancia como plataforma de lanzamiento de cara a las elecciones legislativas previstas para el otoño de una oposición muy dividida y frágil, el verdadero valor del Congreso radicaba en el hecho de que se hubiera celebrado, pues era una muestra más de la voluntad liberalizadora del nuevo primer ministro. ${ }^{24} \mathrm{El}$ movimiento democrático necesitaba de un largo periodo de maduración y debía ser además el primer interesado en el éxito del proyecto de Marcelo Caetano. Al fin y al cabo, solo el profesor podía "conducir a Portugal progresivamente hacia el estado democrático de derecho." ${ }^{25}$

En armonía con los consejos del embajador, el SPD concentró sus esperanzas de evolución positiva en Portugal en Marcelo Caetano y se mostró distante con los compañeros socialistas. En febrero de 1969, Willy Brandt visitó por unas horas Lisboa para encontrarse con su homólogo Franco Nogueira, con quien debatió sobre el acercamiento de Portugal a la CEE. ${ }^{26}$ La visita significó un duro golpe para la oposición democrática y sobre todo para la ASP, que la consideró como una intolerable demostración de amistad con los "fascistas portugueses". ${ }^{27}$ En verano, Mario Soares viajó a Bonn invitado por la Fundación Ebert para tratar de relanzar la cooperación. Una vez allí, el líder de ASP intentó concertar una entrevista con Willy Brandt, pero en la central del SPD le fue negado el acceso al presidente del partido. Según Robert Lamberg, fue una situación humillante para Mario Soares, que a su partida le dijo: "Por lo menos nos queda en Alemania un amigo fiel, aunque solo sea uno: tu, Roberto." ${ }^{28}$ Poco antes, la ASP había asistido por vez primera, como observadora, a un congreso de la Internacional Socialista, donde se aprobó enviar una delegación a Lisboa durante la campaña electoral para demostrar el respaldo de los socialistas europeos a la lista de Mario Soares. Significativamente, el SPD se distanció de la iniciativa, "no solo por los intereses de la política exterior alemana" sino también por considerarla contraproducente para los propios compañeros de la ASP. ${ }^{29} \mathrm{Si}$ el horizonte democrático en Portugal se alcanzaría exclusivamente en el caso de que Marcelo Caetano triunfase sobre los sectores ultras, no tenía sentido para el SPD promover acciones desde la izquierda europea que pudieran erosionar la posición del primer ministro. La decisión del gobierno luso de expulsar del país a la delegación de la Internacional Socialista liderada por su secretario general, Hans Janitschek, no hizo más que reforzar al SPD en sus puntos de vista. ${ }^{30}$

Aunque rodeada de irregularidades, las elecciones legislativas de octubre de 1969 fueron las más limpias celebradas durante el Estado Novo y posibilitaron que por vez primera accedieran a la Asamblea Nacional miembros de la oposición moderada. El gobierno alemán valoró los comicios de forma muy positiva, por considerarlos un espaldarazo al primer ministro y a su programa de reforma en la continuidad. EI SPD llegó a publicar en su servicio de prensa: "Portugal no es aún un estado

\footnotetext{
${ }^{24}$ Informe de la embajada sobre el congreso de Aveiro, 21.5.1969, PAAA, B 26/399.

${ }^{25}$ Informe de Schmidt-Horix sobre las relaciones gobierno-oposición en Portugal, 26.8.1969, PAAA, B26/399.

${ }^{26}$ Informe del Auswärtiges Amt sobre la visita de Brandt a Lisboa, 10.2.1969, PAAA, B26/400.

${ }^{27}$ Francisco Ramos da Costa a Robert Lamberg, 5.3.1969, AFMS, DRC 04384.001.

${ }^{28}$ Robert LAMBERG, Bootspartie im Acheron. Ein Leben zwischen braunem und rotem Totalitarismus, Zúrich, Verlag Neue Zürcher Zeitung, 2006, p. 347.

${ }^{29}$ Hans-Eberhard Dingels a Hans-Jürgen Wischnewski, 9.10.1969, AdsD, WBA 2/50.

${ }^{30}$ Hans-Eberhard Dingels a Hans-Jürgen Wischnewski, 23.10.1969, AdsD, WBA 2/50.
} 
democrático, pero sin duda hay ya señales en esa dirección." ${ }^{31}$ Los comicios habrían demostrado por lo demás la enorme debilidad de los socialistas y su incapacidad incluso para competir con un mínimo de solvencia con los comunistas, cuya lista electoral había sido mucho más exitosa. Esta situación no tenía visos de cambiar a medio plazo, toda vez que la juventud se estaba radicalizando a marchas forzadas y consideraba a ASP el pálido reflejo de una socialdemocracia europea que hacía el juego al dictador. Para la embajada alemana, a lo máximo que podía aspirar ASP era a que Soares fuera nombrado ministro por su antiguo profesor, siempre en el supuesto de que "Caetano tenga éxito en el inédito intento de llevar al otrora país fascista hacia un orden democrático sin que ocurra una revolución" ${ }^{32}$

Las elecciones en Portugal coincidieron con las de la RFA, de las que saldría el primer gobierno de mayoría socialdemócrata en la historia de la República de Bonn. Willy Brandt ascendía al liderazgo de un país que se había convertido ya en la mayor potencia económica del continente pero que sin embargo apenas tenía peso en la escena política internacional. El nuevo gobierno aspiraba a modificar con esa situación, centrando sus esfuerzos en impulsar la política de distensión y desbloquear la cuestión alemana. En la coalición social-liberal estaban además depositadas enormes esperanzas por parte de la juventud alemana, que había agitado en los últimos años las convenciones de una sociedad muy conservadora y quería ver cómo se plasmaba en leyes las realidades que ya estaban en la calle. Volcado en la Ostpolitik, Willy Brandt aparecía en 1970 como paladín del diálogo y la paz en Europa. Sin embargo, este perfil estaba en flagrante contradicción con la política de su gobierno hacia el África portuguesa. No solamente seguía Bonn vendiendo armas a Lisboa sino que además daba respaldo a la construcción de una presa en Mozambique, que era sí mismo un monumento a la voluntad portuguesa de perpetuarse en el continente negro. Para amplios sectores de la izquierda alemana, esta presa localizada en Cabora Bassa se convirtió en el símbolo de un intolerable neocolonialismo del que Willy Brandt no podía seguir siendo cómplice. ${ }^{33}$

En el gobierno social-liberal convivían dos visiones enfrentadas sobre Portugal y su Imperio. La mayoritaria, defendida por el ministro de Exteriores, el liberal Walter Scheel, el de Economía y el de Defensa, estaba por mantener la venta de armas a Lisboa y la presencia de empresas alemanas en el proyecto Cabora Bassa. La minoritaria la representaba el ministro de Cooperación Económica Erhard Eppler, aunque contaba con el apoyo mayoritario de las bases del SPD y de una parte de los diputados socialdemócratas. Eppler abogaba de forma vehemente por poner la política alemana hacia el Tercer Mundo al servicio de la solidaridad y la legalidad internacional, lo que exigía una total revisión de la relación con el Estado Novo. El canciller Brandt, a quien pronto se le achacará falta de liderazgo, dejó que cada ministro defendiera en público sus ideas, con lo que abrió el camino a los malentendidos.

Desde comienzos de 1970, miembros del ala izquierda del SPD se manifestaron a favor de la independencia de las colonias portuguesas; en abril, miembros del MPLA, FRELIMO y PAIGC visitaron Bonn y fueron recibidos en la central del partido; en agosto, el presidente de Renania del Norte Westfalia, Hans Kühn, afirmó en Lusaka que la Fundación Ebert apoyaba moral y materialmente a

\footnotetext{
31 “Continuan las detenciones en España, Portugal ofrece un panorama confuso", SPD Pressedienst, 27.10.1969.

32 Informe de la embajada alemana sobre Mario Soares, 17.12.1969, PAAA, B26/399.

${ }^{33}$ Rudi MASLOWSKI, Der Skandal Portugal. Land ohne Menschenrechte, Múnich, Hanser, 1971.
} 
aquellos movimientos de independencia. ${ }^{34}$ Estas declaraciones y gestos indignaron al gobierno de Lisboa y desconcertaron al propio ministro de Exteriores de la RFA, quien reclamó del canciller claridad en la posición oficial del gobierno. ${ }^{35}$ Walter Scheel rechazaba el doble juego con Lisboa. Si realmente Bonn quería favorecer una salida al conflicto en África, debía hacer uso del capital de confianza atesorado durante años de amistad con Portugal e intentar estimular a sus líderes a avanzar en la dirección correcta. ${ }^{36}$

Siguiendo este consejo, Willy Brandt envió a su ministro Horst Ehmke a Lisboa con la misión de proponer a Marcelo Caetano respaldo alemán para acelerar la descolonización. Años más tarde, Brandt escribirá a propósito de esta improblable iniciativa: "Me acuerdo de la estupidez que cometimos, cuando en el otoño de 1970 tras acordarlo con [el presidente de Zambia y de la OEA] Kenneth Kaunda sondeamos en Lisboa la posibilidad de modificar el estatus de las posesiones portuguesas en un periodo de diez a quince años. ${ }^{\text {“77 }}$ Marcelo Caetano no prestó el menor interés a la propuesta que Horst Ehmke le presentó y su atención se concentró en venderle las bondades de la reforma constitucional que el dictador preparaba y que según él abriría nuevos horizontes para las colonias. El ministro alemán se llevó la impresión de que el primer ministro deseaba caminar lentamente hacia la descolonización, pero también de que su espacio de maniobra era muy pequeño debido a la enorme presión de los sectores ultras. ${ }^{38}$ La confianza en Marcelo Caetano ni siquiera se pondrá en cuestión semanas más tarde, cuando el Ejército luso intentó derrocar al gobierno de Guinea Conakry por su apoyo al PAIGC de Amircal Cabral. La operación fue un fiasco que provocó un escándalo internacional y dañó la imagen de Caetano. No sin embargo en Bonn, donde se consideró como una "verdad histórica" que la operación había sido una maniobra de los ultras para boicotear los esfuerzos del primer ministro de dar una solución política a la guerra. ${ }^{39}$

Aferrado a la ilusión de que Marcelo Caetano era un liberal camuflado, Willy Brandt siguió dándole su apoyo, por ejemplo acelerando en Bruselas las negociaciones entre Portugal y la CEE que llevarían al acuerdo comercial de 1972, y relanzando la venta de armas a Lisboa. ${ }^{40}$ Cualquier otra opción hubiera sido inconsecuente con la participación de empresas alemanas en el proyecto Cabora Bassa y con la lucha de Occidente contra el comunismo. Incapaz de anteponer la ética a los intereses nacionales en su posición hacia el Estado Novo, el Premio Nobel de la Paz 1971 acabaría siendo objeto de críticas cada vez más ácidas tanto de algunos gobiernos africanos como de sectores de izquierda de la propia RFA.

\footnotetext{
${ }^{34}$ Informe sobre la visita a Bonn de Luis d'Almeida, Armando Ponguene y Alcides Beito, 4.5.1970, AdsD, WBA, A $11.4 / 59$.

${ }^{35}$ Informe sobre las críticas de Lisboa a las manifestaciones de Kühn, 18.9.1970, PAAA, B26/398.

${ }^{36}$ Walter Scheel a Willy Brandt, 16.9.1970, PAAA, B26/398.

${ }^{37}$ Willy Brandt, Begegnungen und Einsichten. Die Jahre 1960-1975, Hamburgo, Hoffmann, 1978, p. 630.

${ }^{38}$ Informe de Horst Ehmke sobre su encuentro con Marcelo Caetano, 8.10.1970, PAAA, B26/398.

${ }^{39}$ Embajada alemana en Lisboa al Auswärtiges Amt, 1.2.1971, PAAA, B26/444.

${ }^{40}$ Informe sobre la colaboración militar con Portugal, 6.7.1972, Bundesarchiv, Coblenza, B136/6897.
} 


\section{El APOYO de LA FundACIÓN EBERT A ACCIÓN SOCIALISTA PORTUGUESA}

Tras su muy tímido inicio en 1967, el proyecto de la Fundación Ebert en Portugal comenzó a ganar impulso durante la primavera marcelista. En noviembre de 1968, Robert Lamberg participó en Lisboa en la cena-homenaje que compañeros y amigos organizaron a Mario Soares a su vuelta del destierro en Santo Tomé. Aprovechando la liberalización anunciada por Caetano, la ASP aspiraba a convertirse en el "punto de cristalización de toda la oposición democrática portuguesa", dijo Soares a Lamberg. El primer paso era abandonar la tabula rasa en términos de infraestructura creando una cooperativa cultural como las que ya tenían por entonces cristianodemócratas y comunistas. Esta cooperativa haría las veces de sede oficiosa de ASP y serviría además para difundir el ideal socialista entre la población. Carentes por completo de medios, los compañeros portugueses pedían a los alemanes que se hicieran cargo de los gastos de instalación y mantenimiento. ${ }^{41} \mathrm{El}$ director general de la Fundación Ebert, Günter Grunwald, analizó la propuesta de Mario Soares junto a otra muy similar del grupo de Enrique Tierno Galván en Madrid, y dio luz verde a ambas. Asegurada la financiación, los socialistas lusos constituyeron en Lisboa en junio de 1969 la Cooperativa de Estudos e Documentação. ${ }^{42}$ Poco más tarde crearon en Oporto Coordenadas-Cooperativa Cultural de Estudos e Documentação. Ambos centros se mantuvieron con el dinero que la responsable de la Fundación Ebert para la península ibérica, Elke Sabiel, entregaba en mano regularmente a los compañeros en Lisboa. ${ }^{43}$

La Cooperativa de Estudos e Documentação celebraba los fines de semana recitales, conferencias de historia, sociología, economía, arte, música o literatura, etc. Para no arriesgar una multa o incluso el cierre, estas actividades no tenían un perfil político muy explícito. Eso les restó atractivo entre los sectores más politizados de Lisboa como los universitarios, que se sentían más interesados por los actos de la cooperativa comunista o incluso del Instituto Alemán, cuyo nuevo director, Carl Meyer-Clason, invitaba a intelectuales de izquierda para irritación del gobierno portugués y del nuevo embajador Eherenfried von Holleben. ${ }^{44}$ Por más que los dirigentes socialistas estuvieran insatisfechos con su escasa proyección, es indudable que las actividades culturales de la Cooperativa de Estudos e Documentação consolidaron la presencia pública de ASP y contribuyeron a ampliar su base de simpatizantes. ${ }^{45}$

El otro gran proyecto en el que se embarcó la ASP a comienzos de los setenta fue el relanzamiento del histórico diario República. Y también aquí la Fundación Friedrich Ebert, como única organización socialista europea, iba a prestar una ayuda esencial. Tras alcanzar un acuerdo con la familia propietaria, los socialistas compraron el periódico en $1970 .{ }^{46}$ República estaba casi en ruinas, y para reflotarlo hacía falta algo más que el entusiasmo de los nuevos propietarios. Mario Soares y sus compañeros pidieron entonces ayuda a la Fundación Ebert, que logró un crédito de 150.000 marcos a fondo perdido del Bank für Gemeinwirtschaft, propiedad de la Confederación Alemana de Sindicatos

\footnotetext{
${ }^{41}$ Informe de Robert Lamberg sobre su viaje a Lisboa, 4.12.1968, Archivo privado de Robert Lamberg.

42 Informe sobre las actividades de la Fundación Ebert en Portugal, 30.1.1970, AdsD, FES Hausakten 973.

${ }^{43}$ Entrevista del autor con Elke Sabiel, Bonn, agosto 2010.

${ }^{44}$ Curt MEYER-CLASON, Diários portugueses, Lisboa, Documenta, 2013.

${ }^{45}$ Susana MARTINS, Socialistas na oposição ao Estado Novo, Cruz Quebrada, Casa das Letras, 2005, pp. 125-128.

${ }^{46}$ Mario Soares a Elke Sabiel, 15.9.1970, AdsD, FES Hausakten 2909.
} 
(DGB). ${ }^{47}$ Esta sustancial ayuda alemana a República nunca sería dada a conocer por los socialistas lusos. Es por ello que los estudiosos del periódico no han sido capaces hasta hoy de encontrar explicación racional a la enorme expansión que vivió en el último periodo de la dictadura, cuando se convirtió en el portavoz de toda la oposición democrática. ${ }^{48}$

En 1970, la primavera marcelista agonizaba y Mario Soares fue forzado a abandonar el país. Si para la ASP en Portugal el exilio de su líder significó un duro golpe, para la proyección internacional y la consolidación de la organización como referente de la oposición al Estado Novo iba a resultar sin embargo providencial. Soares fue clave para fortalecer los lazos de la ASP con los partidos hermanos y para lograr su admisión en la Internacional Socialista en 1972. Pese a ello, los socialistas europeos estuvieron muy lejos de satisfacer a los compañeros lusos. Las constantes llamadas de Soares para aislar al Estado Novo y para apoyar a los socialistas en Portugal no fueron escuchadas. En plena era de la distensión europea, la idea de presionar de cualquier forma a un país miembro de la OTAN estaba fuera de lugar. Aunque no lo verbalizaran, los socialistas europeos habían llegado como los compañeros alemanes a la conclusión de que la única vía que Portugal tenía para alcanzar la democracia era la marcada por Marcelo Caetano. Por ello no se comprometieron de forma consecuente con la ASP. Es en este contexto en el que se explica la trascendencia del apoyo efectivo que Fundación Ebert prestó a los socialistas tanto en Portugal, según vimos, como en Europa.

El leit motiv de la colaboración de la Fundación Ebert con los socialistas portugueses en el exilio consistió en acompañar su trabajo de proselitismo, propaganda y lobby. Una labor que tenía una vertiente muy acusada de promoción de la imagen de Mario Soares como líder del movimiento democrático en Portugal. Esenciales en este sentido iban a ser los medios de comunicación europeos como Le Monde, donde Soares escribió con regularidad. En la RFA, su lanzamiento mediático se inició a mediados de 1970, cuando Der Spiege $\left.\right|^{49}$ le dedicó un reportaje después de que la Fundación Ebert hiciera gestiones ante la redacción. ${ }^{50}$ Soares fue también invitado por los compañeros alemanes a conferencias en Europa y América, que contribuyeron a colocarle bajo el foco de la atención mediática y a ampliar su red de contactos políticos. En 1973, se publicó en alemán su libro Portugal Bailloné. ${ }^{51}$

Gracias a la iniciativa de Mario Soares, la Fundación Ebert pudo lanzar finalmente su programa de becas para estudiantes portugueses. A finales de 1969 cinco universitarios de Lisboa recomendados por el líder de la ASP iniciaron sus estudios en Alemania. Como la mayoría de los c. 100 griegos y españoles becados hasta entonces por la Fundación Ebert, estos estudiantes portugueses eran activos políticamente y encontraron un ambiente muy acogedor en la universidad alemana, epicentro de un movimiento de protesta contra la guerra en África. En colaboración con compañeros alemanes, los becarios portugueses crearon en Stuttgart una asociación de apoyo a los emigrantes y lanzaron la revista $A$ Batalha. Estas iniciativas les colocaron en el punto de mira de su embajada y de la policía alemana. En esta difícil situación, los becarios se sintieron desatendidos por la Fundación Ebert y

\footnotetext{
${ }^{47}$ Günter Grunwald al Bank für Gemeinwirtschaft, 2.10.1972, AdsD, FES Hausakten 2909.

${ }^{48}$ Suzana CAVACO, Mercado Media em Portugal no Período Marcelista, Lisboa, Edições Colibri, 2012, p. 418.

49 "Portugal - Detenciones. El fin de una ilusión”, Der Spiegel, 22/1970.

${ }^{50}$ Elke Sabiel a Mario Soares, 8.9.1970, AdsD, FES Hausakten 2909.

${ }^{51}$ Mario SOARES, Portugal. Rechtsdiktatur zwischen Europa und Kolonialismus, Hamburgo, Rowohlt, 1973.
} 
algunos hasta amenazaron con abandonar la RFA. Para evitar experiencias similares en el futuro, la Fundación Ebert puso freno al programa de becas para portugueses. ${ }^{52}$

Algo más satisfactoria resultó el proselitismo de la ASP entre los emigrantes portugueses. Las condiciones de partida eran malas, ya que al contrario que sus compañeros españoles y griegos, los c. 50.000 portugueses residentes en la RFA a comienzos de los años setenta no mostraban interés por la política y no se movilizaban contra la dictadura en la madre patria. Durante su visita a Bonn en la primavera de 1970, Mario Soares pidió a la Fundación Ebert ayuda para extender el mensaje de la ASP entre sus compatriotas emigrados. Entró así en contacto con el IG Metall, sindicato que había desarrollado una exitosa labor de socialización democrática entre griegos y españoles. ${ }^{53}$ La oficina del IG Metall para españoles, dirigida por el gallego Carlos Pardo, comenzó a orientar su labor de información hacia los portugueses. ${ }^{54}$ Aunque no fuese un éxito rotundo, el trabajo sindical sí contribuyó a despertar en la cerrada colonia portuguesa una cierta receptividad a los mensajes de las organizaciones democráticas. Cientos de trabajadores se afiliaron a los sindicatos y por vez primera portugueses fueron elegidos enlaces en sus fábricas. En este terreno abonado, Mario Soares y sus compañeros pudieron finalmente echar su semilla y recoger los primeros frutos. A comienzos de 1973, la ASP ya tenía agrupaciones en cuatro ciudades de la RFA. ${ }^{55}$

En enero de 1973 la ASP celebró en la Cooperativa de Estudos e Documentação una reunión donde por vez primera se debatió seriamente su conversión en partido. Desde la adhesión a la Internacional Socialista el año anterior, los compañeros del exilio presionaban para que se diera el paso y como argumentos a favor señalaban la creciente presencia de la guerra colonial en el debate europeo, la cercanía de las elecciones legislativas y la crisis del régimen. ${ }^{56}$ Aunque los participantes en la reunión en Lisboa se inclinaron por dejar las cosas como estaban, Mario Soares no cambió su hoja de ruta y solicitó a la Fundación Ebert ayuda para realizar un "mini-congreso" de la ASP en la RFA. ${ }^{57}$ La respuesta positiva fue inmediata y en febrero Elke Sabiel viajó a París y a Lisboa para organizar la logística de una operación que debía permanecer en el absoluto secreto para evitar que la PIDE pudiera boicotearla impidiendo la salida de Portugal de los compañeros del interior. El 17 de abril de 1973 se inició el I Congreso de la ASP en la escuela de formación de la Fundación Ebert en Bad Münstereifel. Mario Soares llevó la voz cantante, exponiendo los motivos que le llevaban a defender la creación de un partido. Tras largos e intensos debates, en la tarde del 19 de abril se aprobó convertir Acção Socialista Portuguesa en Partido Socialista.

La fundación del Partido Socialista (PS) coincidió con un grave empeoramiento de la imagen internacional del Estado Novo a causa de la situación cada vez más crítica en las colonias. En este

\footnotetext{
52 Svenja LÄNDER, A BATALHA, Exilerfahrung und politische Aktivitäten der portugiesischen Stipendiatengruppe der Friedrich-Ebert-Stiftung (1969-1974), tesina de fin de carrera, Humboldt Universität Berlin, 2013.

53 Antonio MUÑOZ SÁNCHEZ, “Una introducción a la historia de la emigración española a la República Federal de Alemania (1960-1980)", Iberoamericana, XII, 46 (2012), pp. 23-42.

${ }^{54}$ Entrevista del autor con Carlos Pardo, Mazagón, mayo 2013.

${ }^{55}$ Susana MARTINS, Socialistas na oposição ao Estado Novo, p. 140.

${ }^{56}$ Susana MARTINS, “A fundação do Partido Socialista em 1973”, en: Vitalino CANAS (org.), o Partido Socialista e a Democracia, Oeiras, Celta Editora, 2005, pp. 29-49.

${ }^{57}$ Mario Soares a Elke Sabiel, 24.1.1973, AdsD, FES Hausakten 12783.
} 
contexto, Mario Soares pudo desplegar una exitosa campaña de promoción de su partido. El momento culminante fue en julio de 1973, cuando el Labour Party le invitó a participar en los actos de protesta contra la visita de Marcelo Caetano a Londres. En aquellos meses, Mario Soares fue recibido en muchas capitales europeas por dirigentes socialistas, con quienes dio ruedas de prensa y firmó manifiestos conjuntos. ${ }^{58}$ La visibilidad lograda por el PS en Europa tuvo el deseado efecto en Portugal, donde el régimen lanzó histéricos ataques contra Mario Soares, a quien acabó así por convertir en la figura más popular del movimiento democrático.

Todas estas conquistas de los socialistas portugueses no sirvieron sin embargo para convencer al SPD de modificar su tradicional frialdad para con Mario Soares y sus compañeros. Forzado por la presión de sus propias bases, indignadas por la brutalidad de la guerra colonial portuguesa, el SPD no tuvo más remedio durante 1973 que hacer claros gestos de distanciamiento con el Estado Novo, pero estos se iban a restringir a su policía africana. Tras conocerse la matanza cometida por los portugueses en Wiriyamu (Mozambique), el SPD recibió en Bonn a miembros de los movimientos de liberación y el ministro Hans Eppler se enzarzó en una polémica pública con el embajador portugués tras declarar que no debía tolerarse que se repitiera un nuevo Vietnam en África. ${ }^{59}$ Por cuanto toca a la situación interna de Portugal, el SPD mantuvo sin embargo su tradicional discreción y marcó distancias con los socialistas. Como de costumbre, el SPD no invitó a los compañeros lusos a su congreso, celebrado en Hannover en abril, y tampoco envió días más tarde a ningún miembro relevante al congreso fundacional del PS. Las peticiones de Soares para ser recibido en Bonn no fueron atendidas. ${ }^{60}$ Además, al igual que en el año 1969, el SPD no quiso participar en la misión de la Internacional Socialista para supervisar las elecciones legislativas de $1973 .^{61}$

La situación solo cambiaría a comienzos de la primavera de 1974 tras un muy argumentado apelo de la Fundación Ebert a la dirección del SPD para que respondiera finalmente a la oferta de diálogo de los compañeros lusos. ${ }^{62}$ El 6 de abril, Mario Soares participó en Colonia en un acto político ante 200 trabajadores portugueses y se reunió con los miembros del departamento de relaciones internacionales del SPD Hans-Eberhard Dingels y Veronika Isenberg, quienes le comunicaron la decisión de su partido de invitar a una delegación del PS a visitar Bonn. Mario Soares sorprendió entonces a sus interlocutores afirmando que existía un plan de los militares para derrocar al régimen de Marcelo Caetano y poner fin a la guerra colonial. Los socialistas mantenían contacto desde hacía meses con algunos conspiradores, entre quienes se contaba el general Antonio de Spínola. Este incluso habría confeccionado una lista de posibles ministros de un gobierno de transición, en la que aparecían tres socialistas, uno de ellos Mario Soares como responsable de Exteriores. ${ }^{63}$ El informe de la entrevista con

\footnotetext{
${ }^{58}$ Susana MARTINS, Socialistas na oposição ao Estado Novo, pp. 220 y ss.

${ }^{59}$ Informe de Hans-Eberhard Dingels sobre la entrevista, 14.8.1973, AdsD, Archiv Helmut Schmidt 8998.

${ }^{60}$ En octubre, el secretario del PS escribió al SPD: "Para nosotros es muy importante poder explicaros en detalle qué es nuestro partido y también daros a conocer cómo vemos la situación en Portugal. Al mismo tiempo, queremos profundizar en nuestras relaciones fraternales y saber si podemos contar con vuestra solidaridad." Mario Soares a Hans-Eberhard Dingels, 2.10.1973, AdsD, SPD Parteivorstand 11159.

${ }^{61}$ Guillaume DEVIN, L'Internationale Socialiste, París, Presses de la FNSP, 1993, pp. 184 y ss.

${ }^{62}$ Günter Grunwald a Hans-Jurgen Wischnewski, 5.2.1974, AdsD, FES Hausakten 2972.

${ }^{63}$ Informe reservado sobre el encuentro con Soares en Colonia, 8.4.1974, AdsD, WBA, Bundeskanzler 30.
} 
Soares fue enviado inmediatamente a la Cancillería con la recomendación de que se diera a conocer cuanto antes al gobierno americano. ${ }^{64}$ Sólo el 16 de abril, Willy Brandt ordenó a su secretario de Estado Egon Bahr que pasara la información a Washington. ${ }^{65}$

El 23 de abril de 1974 Mario Soares y Francisco Ramos da Costa viajaron a Bonn para una estancia de tres días invitados por el SPD. La última jornada, el jueves 25 , el secretario general del PS debía ser recibido por vez primera por el presidente del SPD y canciller federal, Willy Brandt. En sus diversos encuentros, entre otros con el ministro de defensa Georg Leber el día 24, Mario Soares volvió a hablar del plan golpista, aunque esta vez de manera más vaga de cuanto lo había hecho en Colonia. Soares se centró en dibujar una situación de crisis terminal del Estado Novo y en presentar a su partido como un partenaire fiable del SPD en el proceso de transición previsiblemente convulso que se iba a producir. Los informes del SPD sobre la visita de la delegación del PS no transmiten la sensación de que Bonn tomase en serio la idea de Soares de que Caetano estaba al borde del abismo. Lo más relevante de la visita para los alemanes fue descubrir que el PS era un partido moderado y constructivo al que quizás había ignorado durante demasiado tiempo: "Soares es un hombre muy sensato, y sin duda alejado de falsas emociones (...) por lo que sería interesante no sólo para nosotros sino también para otros miembros de la Alianza [Atlántica] mantener buenas relaciones con este hombre y su grupo." ${ }^{66}$

Nadie en el SPD ni en el gobierno alemán podía imaginar cuán importantes iban a llegar a ser efectivamente las relaciones con Mario Soares y su grupo a partir de entonces, si bien en unas circunstancias bien distintas a las que habían llevado a dos veteranos exiliado lusos a buscar ayuda en Bonn. A las seis y media de la mañana del 25 de abril, Mario Soares fue despertado en su habitación del Hotel Bristol por una llamada de Veronika Isenberg: Radio París informaba de que algunos cuarteles en Portugal estaban movilizados. "iSon los nuestros!”, exclamó Soares, y rápidamente buscó la manera de regresar a Francia. ${ }^{67}$ No se produjo por tanto el tan esperado encuentro con el canciller Willy Brandt, a quien en todo caso Mario Soares tendrá muchas ocasiones de tratar a partir de aquel día en que comenzaron a florecer las relaciones entre la socialdemocracia alemana y el socialismo portugués.

\section{LA IMPLOSIÓN DE LA DICTADURA Y LOS PRIMEROS MESES DE LA REVOLUCIÓN DE LOS CLAVELES}

El inesperado golpe de estado del Movimiento de las Fuerzas Armadas (MFA) que derrumbó al Estado Novo, y la fiesta de la libertad que se desató en Portugal fueron seguidas en la RFA, como en el resto del mundo, con gran simpatía. Muy pronto, sin embargo, surgieron las dudas en vista de los gigantescos desafíos que Portugal afrontaba, la escasa preparación de unos militares metidos a gobernantes, el contexto de crisis económica mundial y el enorme peso del Partido Comunista Portugués (PCP). La dificultad para seguir la dinámica nerviosa de los acontecimientos en Lisboa, el arraigado anticomunismo de la cultura política alemana y no en último lugar los prejuicios culturales, favorecieron que entre los sectores conservadores de la RFA aquellas dudas se convirtieran rápidamente en inquietud. A la visión más pesimista se abonaron desde primera hora los influyentes

\footnotetext{
${ }^{64}$ Hans-Eberhard Dingels a Dieter Schilling, 9.4.1974, AdsD, WBA, Bundeskanzler 30.

${ }^{65}$ Dieter Schilling a Egon Bahr, 16.4.1974, AdsD, WBA, Bundeskanzler 30.

${ }^{66}$ Hans-Eberhard Dingels a Willi Berkhan, 24.4.1974, AdsD, SPD Parteivorstand 11159.

${ }^{67}$ Entrevista del autor con Veronika Isenberg, Barcelona, diciembre 2014.
} 
diarios Frankfurter Allgemeine Zeitung y Die Welt, no casualmente los únicos que habían defendido hasta el fin a Marcelo Caetano. ${ }^{68}$ Sus corresponsales en Madrid, que como el resto de periodistas alemanes intentarán durante los meses siguientes el imposible de explicar a sus lectores la Revolución con fugaces visitas a Lisboa, sentenciaron apenas pasados unos días del golpe que aquel experimento político estaba "amenazado por todos lados". Ni el fuerte liderazgo del general conservador Antonio de Spínola, ni la disciplina con la que la población celebró el 1ํ de Mayo, ni el pathos grave y equilibrado del MFA, ni las llamadas a la moderación de los comunistas debían llevar a engaño. Si Portugal era "de este mundo" el espíritu de unidad no tardaría en disiparse y el país entraría en una espiral de tensión y violencia que le arrastraría al caos. Un día, se atrevía a pronosticar uno de esos corresponsales alemanes, Walter Haubrich, los relajados y sonrientes soldados que se veían por las calles de Lisboa acabarían disparando sobre la misma gente que ahora les abrazaban y regalaban claveles. ${ }^{69}$

Pese a estar inmersos en una grave crisis política que se saldó con la dimisión de Willy Brandt, los socialdemócratas alemanes reaccionaron con celeridad al cambio de régimen en Portugal y buscaron la forma de contribuir a que no se cumplieran los pronósticos más pesimistas. Tres fueron las líneas de acción que el gobierno de Helmut Schmidt se planteó para intentar influir positivamente en el proceso de transición: respaldar a los nuevos dirigentes a nivel europeo, por ejemplo en una renegociación del Acuerdo Portugal-CEE de 1972; apoyar económicamente, ya a nivel bilateral ya movilizando créditos internacionales; y cooperar con los partidos democráticos buscando su fortalecimiento. Durante los primeros meses de la Revolución, el atomizado y mal avenido poder en Lisboa focalizó su atención en la resolución de la cuestión colonial y no fue capaz de definir otras cuestiones clave como qué modelo económico quería para Portugal o cual había de ser la relación con la CEE. De esta forma, Lisboa no pudo explotar la línea de ayuda económica que Bonn había propuesto ni tampoco solicitó su apoyo para abrir negociaciones en Bruselas. Impedida de momento la cooperación a nivel estatal, a la RFA le quedará como vía principal de influencia el respaldo a los partidos políticos. Dada la desorientación del centro-derecha tras el 25 de abril, liberales y conservadores alemanes demorarán meses en encontrar un socio viable en Portugal, y solo los socialdemócratas podrán desde muy pronto explotar al máximo esta diplomacia paralela. La relación con el PS, durante años un elemento marginal en el conjunto de la policía de la RFA hacia Portugal, pasaba así de un día para otro a situarse en su mismo centro. ${ }^{70}$

Por su peso en la política europea, el SPD fue objetivo prioritario del PS en su búsqueda de apoyos externos, que Mario Soares inauguró durante la gira continental que realizó a petición de la Junta de Salvación Nacional en la primera semana de mayo. Con la intención de que su visita tuviera el mayor impacto en Portugal, el líder del PS fue recibido por Willy Brandt no en su calidad de presidente del SPD sino de canciller. Mario Soares presentó al PS como pieza clave para el triunfo de la democracia en Portugal, pues dado el desprestigio del centro y la derecha por su colaboración con la dictadura los

\footnotetext{
${ }^{68}$ Manuel de MATOS, Das Bild Portugals in der öffentlichen Meinung der Bundesrepublik Deutschland, 1961-1975, tesis doctoral, Rheinischen Friedrich-Wilhelms-Universität Bonn, 1977, p. 348.

69 "Fin de un sueño", Frankfurter Allgemeine Zeitung, 27.4.1974; “Portugal ensaya la libertad”, Die Welt, 29.4.1974; "Oportunidad democrática de Portugal”, Frankfurter Allgemeine Zeitung, 2.5.1974.

${ }^{70}$ Para un análisis exhaustivo sobre el SPD y el 25 de Abril, véase MÓNICA FONSECA, É Preciso Regar os Cravos! A Social-democracia alemã e a transição para a Democracia em Portugal (1974-1976), tesis doctoral, Instituto Universitário de Lisboa, 2011.
} 
socialistas eran los únicos que podían "contener a los comunistas". ${ }^{71}$ Pero para desarrollar su enorme potencial y vencer la batalla política al partido de Álvaro Cunhal, los socialistas debían salvar la enorme distancia que en términos de implantación e influencia les separaba de los comunistas, lo cual pasaba necesariamente por una masiva ayuda de los compañeros europeos. ${ }^{72}$

En coordinación con el SPD y el gobierno alemán, la Fundación Ebert se puso manos a la obra para responder a la llamada de Mario Soares. La segunda semana de mayo, Elke Sabiel viajó, acompañada de un alto funcionario del Ministerio de Cooperación Económica, a Lisboa con la intención de concebir junto a los compañeros lusos un plan de ayuda inmediato al PS. La amiga alemana que tanto les había ayudado durante la dictadura fue recibida con honores en la Cooperativa de Estudos e Documentação, convertida en el cuartel general provisional del PS. Misma acogida tuvo en República, donde los compañeros pidieron que se les enviara de manera urgente desde Alemania rollos de papel, imposible de encontrar en Portugal ante la explosión de venta de periódicos desde el 25 de abril. En su informe sobre la visita, Elke Esters marcó como prioridad absoluta ayudar al PS a salir de las catacumbas de la clandestinidad y tender puentes con una sociedad políticamente virgen. Un reto inmenso para una organización con menos de un centenar de afiliados, que carecía de la más mínima infraestructura y en la que había un absoluto desconocimiento sobre técnicas de propaganda, proselitismo, etc. ${ }^{73}$ En base a las recomendaciones de Elke Esters, la Fundación Ebert concibió un plan de acción en Portugal que en cuestión de días recibió el visto bueno del gobierno alemán. Sus dos puntos esenciales eran el sostenimiento económico de las oficinas que el PS fuera abriendo por el país y la organización de cursos de formación para sus cuadros. El proyecto contaría hasta diciembre de 1975 con un presupuesto de 2,5 millones de DM, que se canalizarían a través de la recién creada Asociación Antonio Sergio. ${ }^{74}$

A comienzos de julio llegó a Lisboa para una misión de seis semanas Günter Wehrmeyer, especialista en formación enviado por la Fundación Ebert para asesorar al PS. Inmersos en el torbellino de la alta política, los dirigentes socialistas habían desatendido totalmente al partido. En términos de organización, todo estaba por hacer. La solidaridad europea se había activado, pero era insuficiente. Según Mario Soares, los comunistas recibían 8 millones de DM mensuales de los países del Este, con los que podían financiar unos mil liberados, mientras el PS apenas tenía diez. Disciplinado y dinámico, el PCP infundía respeto. A su lado, los socialistas le parecían a Wehrmeyer "un grupo de aficionados". Así lo constató en un acto conjunto del PS y el PCP de apoyo al MFA, y que fue monopolizada por los comunistas y sus mensajes de unidad de la izquierda: "tras una noche así parece del todo improbable que el PS tenga la mínima oportunidad de imponerse a los comunistas." La presencia territorial socialista seguía siendo muy débil. Por temor a la infiltración de oportunistas y de comunistas, el PS miraba con lupa las peticiones de afiliación y no hacía apenas campañas de proselitismo. Los miembros del partido eran profesionales liberales y estudiantes; no había un solo trabajador. La formación era deficiente, muchos no conocían siquiera el programa de su partido y eran incapaces de diferenciar entre

\footnotetext{
${ }^{71}$ Informe de la Cancillería sobre el encuentro de Mario Soares con Willy Brandt, 3.5.1974, PAAA, Zwischenarchiv 102445.

72 Informe de Veronika Isenberg sobre la visita de Soares a Bonn, s.f., AdsD, SPD Parteivorstand 11484.

${ }^{73}$ Informe de Elke Sabiel y Winfried Böll sobre su visita a Lisboa, 14.5.1974, AdsD, NL Bruno Friedrich 1537.

74 Acuerdo entre la Fundación Ebert y la Asociación Antonio Sergio, 28.6.1974, AdsD, FES Hausakten 12800NL Bruno Friedrich 1537.
} 
comunismo y socialismo democrático. Günter Wehrmeyer impartió seminarios a los compañeros del PS sobre los temas más variados, como teoría y praxis del socialismo democrático, relación con otras fuerzas políticas, técnicas de propaganda, proselitismo, financiación, contabilidad, etc. Sus explicaciones se ilustraban con material del SPD traducido apresuradamente al español y al portugués. En Sacavem, Wehrmeyer creó una "agrupación modelo": alquiló el local durante seis meses, formó a los cuadros y les ayudó a poner en marcha sus propias formas de recaudación y afiliación. ${ }^{75}$

Convencido de que el PS debía concentrarse en el paciente trabajo de organización, el SPD no quiso en los primeros meses de la Revolución enviar a Lisboa personalidades de alto rango, como los compañeros portugueses reclamaban. Así, mientras los socialistas franceses desplazaron a Lisboa una delegación de postín con François Mitterrand al frente, el SPD se contentaría con enviar aquel verano de 1974 al secretario de Estado Hans-Jürgen Wischnewski y al diputado Bruno Friedrich. Ambos se reunieron con ministros, expresaron su simpatía por el proceso de democratización, reiteraron la disposición del gobierno de Bonn a aumentar la cooperación económica y participaron en actos del PS. ${ }^{76}$ En línea con los esfuerzos del SPD de contrarrestar el pesimismo de los media conservadores alemanes, Wischnewski y Friedrich declararon que en Portugal la transición política discurría impetuosa pero encauzada bajo el firme mando del prestigioso presidente Antonio de Spínola. La creciente inestabilidad política, la conflictividad social, la proliferación de banderas rojas no debían inquietar al observador foráneo. El izquierdismo del que se habían contagiado los portugueses era apenas una fiebre pasajera y comprensible tras medio siglo de asfixiante dictadura de derechas. Poco a poco el espíritu taimado del pueblo luso reemergería, los partidos moderados vencerían holgadamente las elecciones y a partir de entonces la situación se normalizaría. ${ }^{77}$ Pero la Revolución pronto demostraría que no estaba por dar la razón a los moderados.

\section{DE LA DIMISIÓN DE SPÍNOLA A LA INTENTONA CONTRARREVOLUCIONARIA DEL 11 DE MARZO DE}

\section{5}

La sorprendente renuncia del presidente Spínola a finales de septiembre de 1974 a consecuencia de sus diferencias con el MFA produjo en la RFA una fuerte impresión. Algunos periódicos conservadores reprodujeron íntegro el apocalíptico discurso de dimisión del general y se alinearon con su idea de que Portugal se dirigía hacia el caos: "No tiene sentido seguir observando la escena portuguesa a través de las lentes color de rosa del ministro de Exteriores Mario Soares" ${ }^{78}$, sostenía uno; "En el lugar de la vieja dictadura de derechas se está creando una nueva dictadura de izquierdas", escribía otro. ${ }^{79}$ Los socialdemócratas por su parte criticaron este alarmismo y reiteraron su confianza en el triunfo de la democracia en Portugal, aunque de puertas adentro su optimismo no era tal. ${ }^{80}$ Cada vez más preocupado por la inestabilidad que se iba apoderando del sur de Europa, el gobierno de Bonn

\footnotetext{
${ }^{75}$ Informe de Günter Wehrmeyer sobre su actividad en Portugal, 11.8.1974, AdsD, FES Hausakten 2972.

76 “Buenas conversaciones en Lisboa”, SPD Pressedienst, 28.6.1974.

77 "Friedrich reclama ayuda para Portugal", Süddeutsche Zeitung, 6.8.1974.

78 “El peligro de una guerra civil en Portugal aún no está conjurado", Die Welt, 30.9.1974.

79 “Debacle en Lisboa”, Frankfurter Allgemeine Zeitung, 1.10.1974.

${ }^{80}$ Informe del Auswärtiges Amt sobre Portugal, 4.10.1974, PAAA, Zwischenarchiv 102445.
} 
otorgó enorme importancia al giro a la izquierda que siguió al fin de Spínola. Si Portugal acabara deslizándose hacia una democracia popular, toda la izquierda mediterránea lo vería como un modelo o al menos como una fuente de inspiración. La unión de socialistas y comunistas por la que abogaba François Mitterrand, y que él mismo había defendido de forma estridente durante su visita a Lisboa en julio para embarazo del propio Mario Soares, cobraría entonces un fuerte impulso. Animada por la salida de Grecia de la estructura militar de la OTAN, esta izquierda plural podía reclamar la neutralización del Mediterráneo y dañar el equilibrio de bloques. ${ }^{81}$ Inquietante para Bonn era constatar la actitud que ante esta dinámica endiablada en el sur de Europa estaba adoptando EEUU. Perdida cualquier influencia sobre Grecia con el colapso del régimen de los coroneles e incapaz de evitar la guerra en Chipre, la Administración de Gerald Ford nacía sin el "espíritu de lucha" necesario para enfrentarse al reto izquierdista en Italia y en Portugal, y era muy probable que se dejase sorprender por los impredecibles cambios que se producirían en España tras la muerte de Francisco Franco. ${ }^{82}$ En lugar de demostrar simpatía hacia las nacientes democracias del sur de Europa, disipando así toda sombra de intervención a la chilena, el secretario de Estado Henry Kissinger no tenía problema en sembrar el catastrofismo, declarar a Mario Soares el nuevo Kerensky luso ${ }^{83}$, y proclamar a los cuatro vientos que la crisis del Mediterráneo debía parecer a los soviéticos "like a fulfillment of their prophecy of the internal contradictions of the western world". ${ }^{84}$

En vista de la dejación de funciones de la gran potencia americana, el gobierno de Bonn fue convenciéndose de que Europa debía tomar en sus manos la defensa de los intereses de Occidente en el Mediterráneo. A la RFA le tocaba aquí un papel protagonista, no ya sólo por ser el país más interesado en evitar un avance de las izquierdas que podía quebrar la cohesión de la Alianza Atlántica y dañar seriamente la distensión entre los bloques por la que había apostado con la Ostpolitik, sino también por el peso político que había ido ganando en los últimos años y por su potencial económico, casi intacto en aquel periodo de depresión en cuya resolución estaban absortos todos sus vecinos. Dar un primer impulso a esa respuesta europea a la Revolución de los Claveles y modelarla al gusto alemán fue el leit motiv de la visita de Willy Brandt a Portugal a finales de octubre de 1974. En sus encuentros con el presidente Francisco Costa Gomes y el primer ministro Vasco Gonçalves, el líder del SPD se presentó como portavoz de la Europa progresista que simpatizaba con la Revolución impulsada por el MFA y deseaba contribuir a la consecución de sus objetivos de libertad y justicia social. El PS explotó al máximo la presencia en Portugal del Premio Nobel de la Paz, intentando robar protagonismo mediático al PCP, que esos mismos días celebraba en Lisboa su congreso. El sábado 20, Willy Brandt participó en un mitin del PS caótico para los estándares alemanes en el Teatro Coliseu de Oporto, en el que expresó la solidaridad del SPD y del socialismo europeo con Mario Soares y los demás compañeros portugueses que luchaban por la victoria del "socialismo democrático" ${ }^{85} \mathrm{~A}$ la opinión pública alemana, Willy Brandt

\footnotetext{
${ }^{81}$ Hans-Eberhard Dingels a Hans-Jürgen Wischnewski, 19.8.1974, AdsD, WBA, 2/126.

82 Informe de Klaus Harpprecht sobre su visita a EEUU, noviembre 1974, AdsD, SPD Parteivorstand 11164.

${ }^{83}$ Bernardino GOMES, Tiago Moreira de Sá, Carlucci vs. Kissinger. Os EUA e a Revolução Portuguesa, Lisboa, Dom Quixote, 2008, pp. 85 y ss.

${ }^{84}$ The New York Times, 13.10.1974.

${ }^{85}$ MÓNICA FONSECA, É Preciso Regar os Cravos!, pp. 179 y ss.
} 
lanzó un mensaje tranquilizador, descartando que Portugal pudiera caer en manos comunistas. ${ }^{86}$ Palabras que por lo menos no reconfortaron a la ultraconservadora colonia alemana en Portugal, de la que el cónsul en Oporto escribía: “Estas gentes, que durante el Estado Novo vegetaban aquí como en una reserva natural, están tan traumatizadas [con su caída] que ven inminente la llegada de la dictadura del proletariado en Portugal. (...) No debe por tanto sorprender, que (...) la visita de Willy Brandt con la que se buscaba revalorizar la figura del 'comunista' Mario Soares, les parezca en el mejor de los casos incomprensible." ${ }^{87}$

En las semanas siguientes a su visita a Portugal, el presidente del SPD advirtió en diversos foros europeos de los peligros que se incubaban en el Mediterráneo y reclamó medidas efectivas para atajar los graves problemas económicos y sociales de Grecia y Portugal, que estaban haciendo peligrar sus nacientes democracias. ${ }^{88}$ Predicando con el ejemplo, el gobierno de Helmut Schmidt recibió en Bonn al ministro de Defensa Vítor Alves y analizó con él medidas de cooperación económica. ${ }^{89}$ También visitaron Alemania líderes políticos, como los socialistas Mario Soares y Manuel Tito de Morais, a los que se ofreció dar un fuerte impulso al trabajo de la Fundación Ebert en Portugal. ${ }^{90}$

La vehemente toma de posición en favor de la democracia portuguesa por parte del SPD tuvo un impacto positivo en la RFA, donde ganó terreno la idea de que una implicación europea podía frenar la deriva izquierdista de la Revolución. Esto supuso a su vez una presión extra sobre los conservadores alemanes para mostrar finalmente bandera en Portugal después de meses de absoluta desorientación que era fiel reflejo de la escasa relevancia de las derechas en aquella década dorada de la socialdemocracia europea. Desde el mes de mayo de 1974, la CDU había intentado cooperar con el PPD de Francisco Sá Carneiro, pero este acabó rechazando la invitación para probar suerte con la Internacional Socialista. La única opción viable que le quedó a la CDU fue ligarse al CDS de Diogo Freitas do Amaral, con el que en noviembre iniciaría una relación que se iba a prolongar durante años. ${ }^{91}$ Por lo que se refiere al PPD, a raíz de la visita de Willy Brandt a Portugal, el partido abrió un canal de comunicación con el SPD y la Fundación Ebert, que le ayudaría mediante una organización tapadera. ${ }^{92}$

Como en el resto de Europa occidental, en la RFA la izquierda alternativa puso el contrapunto a la preocupación que Portugal provocaba en el establishment político y económico. El 25 de Abril fue recibido con euforia por esa plural y combativa izquierda, y por toda la RFA surgieron comités de solidaridad con Portugal que editaron boletines, organizaron sesiones de información y recopilaron

\footnotetext{
86 Informe de Hans-Eberhard Dingels sobre la visita de Willy Brandt a Portugal, 22.10.1974, AdsD, SPD Parteivorstand 11305.

${ }^{87}$ Informe del cónsul alemán en Oporto sobre la visita de Brandt, 21.10.1974, PAAA, Zwischenarchiv 102445.

${ }^{88}$ Discurso de Brandt ante el Movimiento Europeo, SPD Pressemitteilungen und Informationen, 19.11.1974.

${ }^{89}$ Notas para el canciller sobre su encuentro con Vítor Alves, 5.11.1974, AdsD, Archiv Helmut Schmidt 6980.

${ }^{90}$ Günter Grunwald a Mario Soares, 15.11.1974, AdsD, FES Hausakten 12783.

91 Matthias STENGER, Transnationale Parteienzusammenarbeit. Die Beziehungen der deutschen und portugiesischen Christlichen Demokraten von der Nelkenrevolution bis zum Vertrag von Maastrich (1974-1992), Dusseldorf, Droste, 2011.

${ }^{92}$ El Institut für Internationale Begegnung, que dependía de la propia Fundación Friedrich Ebert.
} 
fondos para proyectos en el país. ${ }^{93}$. Convencidos de que en la lejana y desconocida tierra lusitana se estaba materializando la tan teorizada y soñada democracia socialista, varios centenares de alemanes se implicaron directamente en su construcción, trabajando de forma altruista en barrios obreros o en cooperativas agrícolas. ${ }^{94}$ Desde su rigidez ideológica, estos jóvenes idealistas veían cómo principal impedimento al triunfo de la pretendida voluntad revolucionaria del pueblo luso la presión de las potencias occidentales y sobre todo de la RFA, dada la enorme penetración económica que había logrado en Portugal durante el Estado Novo. Acostumbrado a que esta izquierda alternativa lo presentase como lacayo del gran capital y del imperio yanki, el gobierno de Bonn no hubiera tomado siquiera nota de la creciente acusación de querer asfixiar el 25 de Abril presentada en sus marginales publicaciones, de no haber sido porque la prensa de Lisboa comenzó a hacerse eco de ellas, estimulada probablemente por la embajada de la RDA. Especial preocupación provocó en el SPD la reproducción en la primera página de algunos diarios de un reportaje del paupérrimo boletín Berliner Extra-Dienst de enero de 1975 que acusaba a los socialdemócratas alemanes de estar urdiendo un golpe de estado en Portugal. ${ }^{95}$ Para hacer el tema más espinoso, el director del panfleto era miembro del SPD. Solo años más tarde se conocería que colaboraba con la Stasi, la policía política de la Alemania comunista. ${ }^{96}$

Ante la imparable radicalización del proceso político en Portugal, los socialdemócratas alemanes se fueron quedando sin argumentos para contradecir a la prensa conservadora en su diagnóstico catastrofista sobre la Revolución, exacerbado a partir de enero de 1975 a raíz de acontecimientos como la agresión de grupos de extrema izquierda al congreso del CDS en Oporto, del que dieron testimonio directo a la opinión pública de la RFA los miembros de la delegación de la CDU liberados por el Ejército tras horas de asedio. ${ }^{97}$ Los siempre animosos compañeros del PS también se habían contagiado del pesimismo y hacían llegar a Bonn mensajes inquietantes sobre supuestos planes del PCP de provocar un golpe reaccionario que exacerbase los ánimos revolucionarios. ${ }^{98}$ Pero no todo eran malas noticias. Tras imponerse al sector izquierdista en un tumultuoso congreso, el sector moderado del PS había pasado finalmente a la ofensiva contra el PCP con motivo de la ley sindical. ${ }^{99}$ Esta reafirmación socialistas a pocos meses de las elecciones fue aplaudida por la prensa alemana, que había dudado de la capacidad de Mario Soares y los suyos para articular una sólida alternativa de izquierdas a la que representaba el carismático e íntegro Álvaro Cunhal. ${ }^{100}$

A partir del mes de febrero de 1975, el PS centró sus esfuerzos en la preparación de las elecciones a la Asamblea Constituyente, y una vez más solicitaron la ayuda de los compañeros

\footnotetext{
${ }^{93}$ Véase el número dedicado a la Revolución de los Claveles en la revista alemana Tranvía, 32 (1994).

${ }^{94}$ Helga M. NOVAK, Die Landnahme von Torre Bela, Berlín, Rotbuch Verlag, 1976.

95 “Cómo se va a hacer un putch en Portugal, cuándo, por qué y por quién”, Berliner Extra-Dienst, 31.1.1975.

${ }^{96}$ Hubertus KNABE, "Frontstadt Berlin. Die geheimen Propagandaaktionen der Stasi", Die politische Meinung, 381 (2001), pp. 33-36.

97 Matthias STENGER, Transnationale Parteienzusammenarbeit, pp. 126 y ss.

${ }^{98}$ Informe de Dingels sobre su conversación con Jorge Campinos, 3.2.1975, AdsD, FES Hausakten 2972.

${ }^{99}$ David CASTAÑO, Mário Soares e a Revolução, Alfragide, Dom Quixote, 2012, pp. 201 y ss.

100 "Socialismo en portugués", Frankfurter Allgemeine Zeitung, 17.12.1974.
} 
alemanes. ${ }^{101}$ En respuesta, la Fundación Ebert se comprometió a financiar la compra de 22 coches con megafonía, sostener 50 liberados del PS durante meses de marzo y abril (el partido tenía por entonces solo 20) y enviar a Lisboa tres expertos alemanes en campañas electorales. Pese al ambiente de tensión política que se vivía en Portugal, cuando los expertos llegaron al país a comienzos de marzo, los compañeros socialistas estaban muy animados y convencidos de sus grandes posibilidades en unas elecciones que habrían de marcaría el inicio del fin de la deriva comunista. ${ }^{102}$ Pero una vez más, la Revolución iba a desmentir a los optimistas.

\section{DEL GOLPE CONTRARREVOLUCIONARIO A LAS ELECCIONES DE ABRIL DE 1975}

Pésimamente planificado, el golpe contrarrevolucionario del 11 de marzo de 1975 fracasó en pocas horas y sus responsables huyeron a España o bien trataron de protegerse tanto de las fuerzas leales como de una población soliviantada que en varias ciudades descargó su rabia arrasando las sedes de los partidos conservadores. Cuatro de los veintisiete oficiales implicados en la conspiración buscaron refugio en la embajada de la RFA en Lisboa, frente a la que se concentraron centenares de izquierdistas que lanzaron proclamas contra el gobierno de Bonn por su supuesta connivencia con la intentona. Cuando a la mañana siguiente el embajador Fritz Caspari fue a negociar la entrega de los militares con el presidente Costa Gomes, su coche fue apedreado y el reingreso en la embajada hubo de realizarlo en una tanqueta. En el MFA nadie tomó sin embargo en serio las acusaciones contra la RFA. Era evidente que el golpe había sido autóctono y tan mal organizado que parecía impropio de un Ejército con amplia experiencia bélica. Como reconocían los militares refugiados en la embajada de la RFA, aquella había sido una acción desesperada para intentar frenar la implantación de una democracia popular. ${ }^{103}$ Irónicamente, el golpe provocó un violento giro a la izquierda, creándose un Consejo de la Revolución que concentró todo el poder y cuyo objetivo declarado fue construir el socialismo en suelo luso. Portugal, sentenciaba uno de los expertos enviados por la Fundación Ebert para apoyar al PS a organizar su campaña electoral, se había convertido de facto en una dictadura militar de izquierdas. ${ }^{104}$

El golpe fallido del 11 de marzo fue visto en Occidente como un acto de total irresponsabilidad de las derechas portuguesas. A un mes de las elecciones para la Asamblea Constituyente que según todas las previsiones iban a dar una victoria absoluta a las fuerzas moderadas, el expresidente y los suyos habían dado la excusa perfecta a los radicales del MFA para perpetuar su control del país más allá de los comicios. En cuanto a qué pasaría a partir de entonces en Portugal y cual debía ser la respuesta desde las naciones amigas, las opiniones en las cancillerías diferían. En Estados Unidos, los acontecimientos en Lisboa se interpretaron como la materialización de la profecía Henry Kissinger en el sentido de que una vez que los comunistas habían entrado en el gobierno era solo cuestión de tiempo que acabaran tomando control de la situación. Washington decidió que había llegado el momento de

\footnotetext{
${ }^{101}$ Informe de la visita de Tito de Morais a Alemania, 25.2.1975, AdsD, FES Hausakten 2972.

102 Véase el testimonio de uno de los expertos, Klaus WETTIG, "Portugal no Ano Zero - 1974-75", Finisterra, 76 (2015), pp. 69-77.

${ }^{103}$ Fritz Caspari al Auswärtiges Amt, 12.3.1975, PAAA, Zwischenarchiv 113503.

${ }^{104}$ Informe de Dieter Schneider desde Lisboa, 16.3.1975, AdsD, FES Hausakten 12800.
} 
plantearse seriamente la expulsión de Portugal de la OTAN. ${ }^{105}$ En el Reino Unido, la reacción del gobierno laborista fue bastante menos alarmista. Londres consideraba que con el golpe la fiebre revolucionaria había ciertamente aumentado en algunas décimas, pero con el tiempo el paciente se estabilizaría. En cuanto al peligro comunista, los laboristas lo relativizaban. El ministro de Exteriores James Callaghan había comido en febrero con Álvaro Cunhal en Lisboa y se había llevado una buena impresión. El líder del PCP le había parecido "nice and sensible" y su intención de crear en Portugal un socialismo con rostro humano, sincera y digna de respeto. Había pues que tener un poco de paciencia y ver como evolucionaba la situación. ${ }^{106}$ Por su parte, el gobierno conservador en París estaba mucho más preocupado que el británico pero consideraba que en el ambiente de efervescencia revolucionaria que se vivía en Portugal tras el golpe no era posible para Occidente influir para reconducir la situación y apostaba por esperar a que las elecciones clarificasen el panorama. ${ }^{107}$

El catastrofismo de EEUU ante los acontecimientos en Lisboa sorprendió y preocupó en Bonn mucho menos que la actitud entre tibia y resignada de las principales potencias de Europa. La inexistencia de un relato común europeo sobre la crisis portuguesa alarmó especialmente a los socialdemócratas alemanes, entre los que apenas se oían ya voces discordantes con la estridente prensa conservadora que, en su rabioso anticomunismo, reducía la complejidad de la Revolución a una toma por etapas del palacio de invierno por parte de los comunistas. ${ }^{108}$ La convicción de que Álvaro Cunhal no dejaría pasar la oportunidad histórica que se le había presentado para hacer realidad su sueño leninista y de que Occidente entretanto se había puesto de perfil, explica la reacción nerviosa de Bonn a los acontecimientos posteriores al 11 de marzo. Tras disolver el III Gobierno Provisional, el Consejo de la Revolución pretendió que en el nuevo gabinete las seis carteras civiles fuesen ocupadas solo por partidos de izquierda. Al serle presentada esta oferta, el PS se negó en redondo y amenazó con no entrar en el gobierno si se excluía del mismo al PPD. Para reforzar su postura, Mario Soares buscó apoyo internacional, y el día 21 hizo llegar a través de uno de los expertos electorales de la Fundación Ebert presentes en Lisboa un SOS personal al canciller alemán Helmut Schmidt. ${ }^{109}$ El contenido del mensaje lo resumiría así el propio Soares horas más tarde a un compañero francés al concluir un mitin de presentación de los candidatos del PS a las elecciones:

La situation est très grave. (...) Le PCP a d'ailleurs I'appui total de Vasco Gonçalves. Le Président de la République est prisonnier. Il y a même eu coup de force à l'intérieur du MFA: le Conseil de la Révolution a été désigné sans aucune consultation, les autres instances ayant été dissoutes. Actuellement on nous propose [un gobierno en el que] de fait, le travail, I'agriculture, les affaires sociales seraient pour les communistes ou leurs satellites. Voilà où nous en sommes à cette heure. En outre, la presse, parlée, écrite, télévisée est entre les mains des communistes qui ont organisé des conseils de typographes, de rédacteurs, de techniciens. Je

\footnotetext{
${ }^{105}$ Bernardino GOMES, Tiago MOREIRA DE SÁ, Carlucci vs. Kissinger, pp. 163 y ss.

${ }^{106}$ Embajada de la RFA en Londres al Auswärtiges Amt, 21.3.1975, PAAA, Zwischenarchiv 113503.

${ }^{107}$ Embajada de la RFA en París al Auswärtiges Amt, 21.3.1975, PAAA, Zwischenarchiv 113503.

108 “Golpe a plazos", Frankfurter Allgemeine Zeitung, 28.1.1975.

109 Informe de Peter Ruthmann, 21.3.1975, AdsD, NL Bruno Friedrich 1537.
} 
suis pratiquement interdit d'antenne. (...) Nous assistons à un processus évident d'instauration d'une démocratie populaire. ${ }^{110}$

Para Mario Soares, no cabía la menor duda de que la propuesta de un gobierno de izquierdas había sido inspirada por Álvaro Cunhal, quien se preparaba ya para un asalto definitivo del poder imitando a sus camaradas de Praga en 1948. Tras recibir el mensaje del líder del PS en la tarde del viernes 21, Helmut Schmidt convocó a su ministro de Exteriores Hans-Dietrich Genscher y a algunos asesores. Este gabinete de crisis concluyó que había que tomar muy en serio la alarma lanzada por Soares y movilizar como él mismo pedía a los gobiernos y a la opinión pública occidentales, así como presionar a Moscú para que frenase al PCP. Esa misma noche el canciller alemán telefoneó a Gerald Ford, Harold Wilson y Valéry Giscard d'Estaing. De fuente "absolutamente fiable", les dijo, el gobierno alemán había tenido conocimiento de que la situación en Portugal era crítica y estaba "en marcha un proceso como en Checoslovaquia hace 27 años". A continuación, Helmut Schmidt les animó a convocar una reunión urgente de la OTAN y a llamar a consultas al embajador soviético. Al mismo tiempo, el Auswärtiges Amt solicitó a la presidencia irlandesa de la CEE que preparase una iniciativa conjunta de los Nueve para protestar ante Lisboa. También se dieron órdenes para comunicar la situación al Papa través del Nuncio del Vaticano en la RFA, y para que el embajador soviético en Bonn compareciera ante el canciller federal a la mañana siguiente. ${ }^{111}$

Siguiendo la petición de Bonn, el secretario general de la OTAN convocó el fin de semana un debate a puerta cerrada sobre Portugal. Para sorpresa del embajador alemán, los colegas europeos allí presentes no compartieron su alarmismo. La situación en Lisboa no les parecía desesperada, y debía además mejorar sensiblemente tras las elecciones. La propuesta alemana para que Occidente exigiera con una sola voz a las autoridades de Portugal que frenasen la radicalización política les parecía errada y contraproducente, pues levantaría acusaciones de interferencia en los asuntos internos de país que solo beneficiarían a los comunistas. Aún más claro fue el rechazo a la idea alemana de presionar a la URSS para que desactivara al PCP. La política de Moscú hacia Portugal desde el 25 de abril, advirtieron, era intachable y de ninguna manera se orientaba a la instauración de un régimen comunista. Amenazar a los soviéticos con un boicot de Occidente a la firma del Acta Final de la CSCE en Helsinki si la Revolución no se reconducía hacia una democracia liberal constituía por ello un absoluto despropósito. ${ }^{112}$ El lunes 24, el rechazo a las recetas de Bonn se manifestaría también en la CEE. En la reunión celebrada en Dublín entre el ministro de Exteriores Garret FitzGerald y los embajadores de los países miembros, el representante alemán pidió una iniciativa conjunta de los Nueve para forzar al Consejo de la Revolución a que desistiera de formar un gobierno sin partidos de centro y derecha. Algunos embajadores apoyaron la idea, pero los de Francia y Gran Bretaña se negaron a secundarla. París no presionaría a Lisboa en ningún caso, mientras Londres había decidido presentar sus argumentos a las autoridades lusas sin contar con la CEE. ${ }^{113}$ Ante la falta de una respuesta común europea, ese mismo día 24 los embajadores en Lisboa de Gran Bretaña, la RFA, Holanda y Bélgica expresaron por separado al

\footnotetext{
${ }^{110}$ Informe del secretario de relaciones internacionales del Parti socialiste Antoine Blanca sobre su conversación con Mario Soares en Lisboa la madrugada del 22 de marzo, s.f., AdsD, SPD Parteivorstand 11490.

${ }^{111}$ Akten zur Auswärtigen Politik der Bundesrepublik Deutschland, 1975, documento 55.

${ }^{112}$ Embajador de la RFA ante la OTAN al Auswärtiges Amt, 22.3.1975 y 24.3.1975, PAAA, B150/325.

${ }^{113}$ Embajador de la RFA en Dublín al Auswärtiges Amt, 24.3.1975, PAAA, B150/325.
} 
presidente Costa Gomes la preocupación de sus respectivos gobiernos por la situación en el país. ${ }^{114}$ Finalmente, el miércoles 26 de marzo se nombró un nuevo gobierno en el que, contra lo previsto, estaba presente el PPD. Para Mario Soares era evidente que el cambio de opinión del Consejo de la Revolución se había debido a la presión occidental y expresó a Helmut Schmidt su agradecimiento por la respuesta que había tenido su SOS. ${ }^{115}$

En Bonn no había sin embargo motivo alguno de satisfacción. En la reunión del gabinete el día 26 de marzo, Helmut Schmidt manifestó su absoluta decepción ante el nulo eco que había encontrado su iniciativa entre los países amigos y lamentó la "escasa actividad del mundo occidental" en la crisis portuguesa, haciendo excepción de la RFA. Las llamadas de Willy Brandt y de otros responsables políticos alemanes en los meses pasados para dar forma a una respuesta europea a los problemas económicos de Portugal no habían llevado a nada. Los aliados no parecían entender que si Portugal se sentía abandonado por Occidente, podía optar por salir de su marco de influencia, poniendo con ello en serio peligro el equilibrio entre los dos bloques. En vista de la actitud blanda de la mayoría de países amigos, Helmut Schmidt decidió que la RFA articulase una ofensiva diplomática para intentar reconducir la Revolución hacia la democracia parlamentaria, y para la que se intentaría ganar al resto de miembros de la CEE e incluso a EEUU. Como primer paso, el canciller ordenó a varios de sus ministros que concibieran una iniciativa de apoyo urgente a Portugal. ${ }^{116}$

El plan de ayuda a Portugal aprobado por el gobierno de Bonn el 9 de abril y dirigido a "evitar la caída del país en el campo comunista", era muy amplio y diversificado. El elemento de más peso era un crédito de 70 millones de DM dirigido a inversiones públicas y la adquisición para la Bundeswehr de munición de fabricación portuguesa por valor de 40 millones de DM. Para reanimar la inversión privada alemana en Portugal, congelada desde el inicio de la Revolución, Bonn propondría a Lisboa la creación de una comisión bilateral. En el ámbito político, se otorgarían más recursos a las fundaciones alemanas para que intensificaran su ayuda a los partidos portugueses y a los sectores moderados de la Intersindical. Además, se ampliaría el programa de visitas de ministros, políticos, periodistas, sindicalistas y empresarios portugueses, con el que se pretendía hacerles sensibles a los encantos del capitalismo renano. En el ámbito cultural, Bonn intentaría frenar la campaña de desprestigio contra la RFA puesta en circulación en Portugal por la prensa cercana a los comunistas y propondría a Lisboa asistencia técnica para introducir la televisión en color. Con respecto a las medidas multilaterales, Bonn apoyaría la concesión a Portugal de una ayuda directa de la CEE y de un crédito del Banco Europeo de Inversiones en condiciones muy favorables. ${ }^{117}$

La celeridad con que el paquete de ayuda a Portugal fue concebido respondió al interés de presentarlo antes de las elecciones a la Asamblea Constituyente. El mismo día de su aprobación el 8 de abril, el gobierno de Bonn lo anunció a bombo y platillo. Poco después, el embajador en Lisboa expuso al primer ministro Vasco Gonçalves los detalles del plan y los medios de comunicación portugueses se

\footnotetext{
${ }^{114}$ Luís NUNO RODRIGUES, Mareschal Costa Gomes no centro da tempestade, Lisboa, Esfera dos Livros, 2008, pp. 232-233.

${ }^{115}$ Akten zur Auswärtigen Politik der Bundesrepublik Deutschland, 1975, documento 66.

${ }^{116}$ Extracto del protocolo de la sesión del gabinete, 26.3.1975, PAAA, Zwischenarchiv 113503.

${ }^{117}$ Informe del Auswärtiges Amt sobre el plan de ayuda, 7.4.1975, PAAA, Zwischenarchiv 110242.
}

HISPANIA NOVA., 15 (2017), págs. 243-273 DOI: https://doi.org/10.20318/hn.2017.3488 
ocuparon profusamente del asunto durante días. ${ }^{118}$ Antes de su puesta en funcionamiento, la iniciativa alemana, dirigida en palabras de Genscher "a abrazar a Portugal", ya había así logrado el deseado objetivo de lanzar a los votantes lusos el mensaje de que en Europa existía una voluntad sincera de contribuir a que su país saliera del marasmo económico. El principal beneficiario interno de esta operación de propaganda debía ser el PS, que había sabido convertir la relación privilegiada con los partidos socialistas europeos y la supuesta capacidad de influencia sobre los gobiernos que estos sostenían en uno de sus principales atractivos. ${ }^{119}$

Entretanto, la campaña electoral ya había comenzado. Intentando romper los pronósticos, los comunistas pusieron en marcha una campaña espectacular, de enorme calidad técnica, perfecta escenificación y desbordantes medios. Así lo constataron Dieter Schneider, Peter Ruthmann y Klaus Wettig, los tres expertos en elecciones enviados por la Fundación Ebert para echar una mano a los compañeros portugueses. Llamativo les resultó a los alemanes las carencias estructurales que aún el PS arrastraba. En la central del partido reinaba una sensación de confusión y desorden. La Comisión Técnica Electoral que debía coordinar la campaña desde Lisboa no cumplía su función correctamente, porque las órdenes que enviaba quedaban atascadas en unas estructuras territoriales intermedias extremadamente frágiles. La propaganda socialista era cuantitativa y cualitativamente insuficiente, los materiales gráficos un trabajo de aficionados y los aparatos de megafonía pésimos. ${ }^{120}$ Preocupados por las acusaciones comunistas de ser meras marionetas del socialismo europeos, los dirigentes del PS no invitaron a personalidades extranjeras para acompañarles en la campaña electoral y pidieron a los compañeros de la Fundación Ebert que se movieran con absoluta discreción. Eso rebajó la capacidad de acción de los expertos alemanes, quienes pese a todo pudieron marcarse un tanto al convencer al PS a concentrar la campaña en su carismático líder. ${ }^{121}$

El resultado de las elecciones a la Asamblea Constituyente celebradas el 25 de abril de 1975 fue recibido con sorpresa y entusiasmo en Occidente. El comentario unánime era que Portugal había votado por la moderación y contra el comunismo. Se verificaba que como venían defendiendo los socialistas europeos con el SPD al frente, existía una oportunidad real para el establecimiento de una democracia en el país. Ahora más que nunca, el mundo libre debía por tanto movilizarse para evitar que el pueblo luso fuese arrastrado al abismo. ${ }^{122}$ La identificación del PS con los socialistas europeos y el apoyo directo de estos jugaron un papel clave en el resultado electoral. Para Mario Soares y los suyos, no había duda de que había sido así y que su deuda era especialmente grande con los colegas alemanes. Semanas más tarde, una delegación de parlamentarios europeos socialistas de visita en Lisboa escuchó

\footnotetext{
${ }^{118}$ Fritz Caspari sobre su conversación con Vasco Gonçalves, 18.4.1975, Zwischenarchiv 110242.

119 Juliet ANTUNES SABLOSKY, O PS e a Transição para a Democracia. Relações com os partidos socialistas europeus, Lisboa, Editorial Notícias, 2000.

${ }^{120}$ Informe sobre una conversación con la delegación de expertos, 16.4.1975, AdsD, FES Hausakten 2972.

${ }^{121}$ Informe de Peter Ruthmann sobre la actividad de la delegación, s.f, AdsD, FES Hausakten 12799.

122 "Confianza en el desarrollo portugués", SPD Pressedienst, 28.4.1975; "Portugal se decide por el camino europeo", Die Welt, 28.4.1975; “Aun no se ha perdido Portugal”, Frankfurter Allgemeine Zeitung, 29.4.1975.
} 
de boca del tesorero del PS que el mérito de la victoria era tanto de su propio partido como del SPD y de la Fundación Ebert. ${ }^{123}$

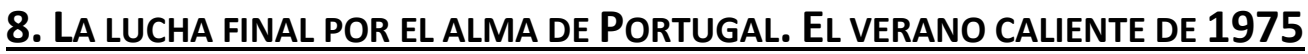

Las elecciones a la Asamblea Constituyente no modificaron de forma inmediata el panorama político, pero sí activaron una serie de dinámicas de fondo que en pocos meses iban a provocar el fracaso del proyecto de creación de un socialismo a la portuguesa. Durante este periodo, la implicación de las potencias occidentales en favor de las fuerzas moderadas fue masiva y buscada además por los propios actores políticos nacionales, con el PS al frente. Liderando esta suerte de "intervención pacífica" se encontraba la RFA, que recurrió a toda su maquinaria diplomática, su enorme peso económico y sus poderosos partidos, fundaciones y sindicatos para intentar favorecer por los más diversos canales a aquellas fuerzas en Portugal que defendían la instauración de una democracia de corte europeo.

El gobierno de Bonn consideró uno de los objetivos prioritarios de su política hacia Portugal después de las elecciones establecer en un diálogo constructivo con el Consejo de la Revolución, el gremio militar que detentaba el control político en el país tras el 11 de marzo. Informaciones de primera mano sobre los miembros de este núcleo duro del poder revolucionario, recogidas por la embajada en Lisboa, permitieron muy pronto a los dirigentes de la RFA albergar esperanzas en una evolución positiva. Por lo general, los miembros del Consejo de la Revolución no tenían capacidad para gobernar, se sentían inseguros y eran muy influenciables, sobre todo si se les presentaban argumentos de carácter técnico. El ascendente del PCP sobre el MFA era más bien escaso, e incluso se percibía en este un malestar latente por el enorme peso político que el partido había adquirido desde el 25 de Abril. El Consejo de la Revolución no pretendía alejar a Portugal del bloque occidental. Sus críticas a la OTAN se debían solo al rencor acumulado hacia EEUU por haber mostrado mucho menos comprensión con la Revolución que con el Estado Novo. De la misma forma, no existía hostilidad alguna hacia las democracias europeas, e incluso muchos oficiales admiraban a Suecia y la RFA por su potente estado de bienestar. $^{124}$

Buscando potenciar el sector templado dentro del Consejo de la Revolución, en el mes de mayo el gobierno de la RFA invitó a visitar Bonn a su figura más destacada, el ministro de Exteriores Ernesto Melo Antunes. El ministro portugués fue recibido por el canciller Helmut Schmidt y el ministro de Exteriores Hans-Dietrich Genscher, a quienes sorprendió muy positivamente por su realismo y su orientación europeísta. Melo Antunes consideraba como prioridad absoluta de su gobierno buscar una salida a la profunda depresión económica en que Portugal se encontraba. La puesta en marcha de medidas constructivas era sin embargo bloqueada por los comunistas, que ignorado la voluntad del pueblo expresada en las urnas se habían embarcado en una alocada carrera por la hegemonía. El PCP, sentenció, era un simple "vasallo de Moscú". Señaló el ministro que en Portugal había una fuerte corriente de opinión, a la que él pertenecía, favorable a estrechar lazos con Europa. ${ }^{125}$ En fin, Melo

\footnotetext{
123 Informe de Wilhelm Dröscher sobre la visita de la delegación socialista del Parlamento Europeo a Portugal, 11.6.1975, AdsD, NL Bruno Friedrich 1537.

124 Informe del Dr. Laub sobre su viaje a Portugal, 25.4.1975, PAAA, Zwischenarchiv 113503.

125 Informe sobre la conversación de Antunes con Genscher en Bonn, 19.5.1975, Akten zur Auswärtigen Politik der
}

HISPANIA NOVA., 15 (2017), págs. 243-273 DOI: https://doi.org/10.20318/hn.2017.3488 
Antunes abogaba como venía haciendo Mario Soares desde un año atrás, por una implicación masiva de la Europa democrática en Portugal y bendecía por ello todas las iniciativas que estaba tomando el gobierno de Bonn. A raíz de esta visita a Bonn, el ministro de Exteriores luso se convirtió para el gobierno de Helmut Schmidt en un punto de apoyo fundamental para el despliegue de su estrategia hacia el Portugal revolucionario.

Una de las prioridades de Bonn tras las elecciones de abril de 1975 consistió en atraer a Washington a la política de cooperación con Lisboa que los propios sectores moderados del MFA liderados por Melo Antunes reclamaban. No resultaba una labor fácil, toda vez que EEUU había asumido tras el 11 de marzo que Portugal estaba irreversiblemente perdido para Occidente, y su única preocupación era encontrar la forma de aislar al país para que no se convirtiese en una "quinta columna de Moscú". ${ }^{126}$ Tras la fría respuesta de Henry Kissinger al plan de ayuda alemán anunciado a comienzos de abril y a las advertencias de Helmut Schmidt sobre los daños irreparables que causaría a la distensión europea la expulsión de Portugal de la Alianza Atlántica con la que especulaba el secretario de Estado, el canciller decidió recurrir a un tono más asertivo con el amigo americano. A mediados de mayo, Bonn comunicó a Washington que si EEUU intentaba forzar la salida de Portugal de la OTAN, encontraría la oposición férrea de Europa y dañaría seriamente las relaciones transatlánticas. La Alianza Atlántica, que no había considerado como un problema tener en su seno a regímenes autoritarios como el Estado Novo, debía ahora demostrar su fortaleza cohabitando por algún tiempo con un régimen de izquierdas. ${ }^{127}$

Kissinger dio muestras de haber recibido el mensaje durante su encuentro con Genscher y Schmidt pocos días más tarde en Bonn. El secretario de Estado reiteró a los colegas alemanes su "profunda convicción" de que Portugal estaba prácticamente en manos de los comunistas y de que debía por tanto ser expulsada de la OTAN. Ahora bien, esta interpretación personal no tendría ya influencia práctica en la formulación de la política americana. ${ }^{128}$ Pese a su íntima certeza de que cooperar con un gobierno dominado por comunistas era erróneo, Washington pensaba anunciar un plan de ayuda económica de 25 millones de dólares para Portugal. Durante el verano caliente de 1975, a Kissinger no le faltarán motivos para mantener su profundo escepticismo hacia la estrategia europea de cooperación liderada por la RFA, pero ya no volverá a plantear una alternativa a la misma. ${ }^{129}$

Otro eje de la política de la RFA hacia Portugal en los meses centrales de 1975 consistió en respaldar de forma enérgica al PS en su estrategia de "conflicto limitado" con el MFA y el PCP, con la que Mario Soares y sus compañeros perseguían hacer valer su victorial electoral ganando cuotas de poder en detrimento de los comunistas, que se habían infiltrado masivamente en la Administración con el beneplácito del primer ministro Vasco Gonçalves. Esta reivindicación de su legitimidad electoral era desplegaba por los socialistas sobre todo a través de los medios de comunicación cercanos y de movilizaciones en la calle, hasta poco antes casi monopolio de los comunistas. Ambos elementos

\footnotetext{
Bundesrepublik Deutschland, 1975, documento 122.

${ }^{126}$ Embajador de la RFA en Washington sobre Kissinger y Portugal, 18.4.1975, PAAA, Zwischenarchiv 113503.

${ }^{127}$ Informe de la conversación de un enviado de Schmidt con Helmut Sonnenfeldt, 15.5.1975, PAAA, B150/329.

${ }^{128}$ Informes de las encuentros de Kissinger con Genscher (20.5.1975) y Schmidt (22.5.1975), PAAA, B150/329.

${ }^{129}$ Bernardino Gomes, Tiago Moreira de Sá, Carlucci vs. Kissinger, pp. 262 y ss.
}

HISPANIA NOVA., 15 (2017), págs. 243-273 DOI: https://doi.org/10.20318/hn.2017.3488 
confluyeron en el caso República. ${ }^{130}$ Lo que en principio no era sino un conflicto laboral ajeno por completo al PCP, fue denunciado urbi et orbi por Mario Soares como una operación de los comunistas para acabar con una de las pocas voces que se oponía a su supuesto plan totalitario, obligando así al Consejo de la Revolución a tomar postura. Aunque la sobreactuación de los socialistas era evidente, en la RFA el establishment asumió sin más su argumentación y respondiendo a la insistente petición de Soares, los socialdemócratas realizaron un enorme despliegue político y mediático defendiendo la posición del PS. Informaciones objetivas sobre el caso República apenas aparecieron en los medios de comunicación mayoritarios de la RFA, donde se aplicó censura con los pocos periodistas que se negaban a subir a la ola anticomunista. ${ }^{131}$

El apoyo exterior resultó crucial para fortalecer la posición del PS en un conflicto que terminó dividiendo a la sociedad portuguesa, exacerbando las tensiones en el seno del Consejo de la Revolución y debilitando enormemente a los comunistas. A mediados de julio, el PS elevó su presión al límite, abandonando junto al PPD el gobierno y sacando a la calle en Oporto y Lisboa a cientos de miles de personas, al tiempo que en el norte conservador se ponía en marcha con la bendición de la Iglesia una cruzada contrarrevolucionaria que se saldó con la quema de centenares de sedes del PCP y la desaparición de facto del partido de toda la región. Para reforzar al PS en aquel momento crítico, Willy Brandt defendió durante sendos viajes a Moscú y Washington la postura de los compañeros socialistas lusos y, a comienzos de agosto reunió en Estocolmo a las principales figuras del socialismo europeo que habían participado en la firma del Acta Final de la CSCE en Helsinki para proponer la creación del Comité de Ayuda y Solidaridad con la Democracia y el Socialismo en Portugal. ${ }^{132}$ En septiembre, Willy Brandt celebró junto a Mario Soares en un mitin de solidaridad del SPD con el PS en un pabellón de Frankfurt, ante el cual se concentraron centenares de izquierdistas con Daniel Cohn-Bendit al frente al grito de "Socialismo sí, Soares no" y "RFA y capital - fuera vuestras manos de Portugal". ${ }^{133}$ Entretanto, en Portugal se había puesto en circulación con el masivo apoyo económico y logístico de la Fundación Ebert el jornal $A$ Luta, que venía a sustituir a República como portavoz de los socialistas. ${ }^{134}$

El instrumento en el que la RFA depositó mayores esperanzas para influir sobre los acontecimientos en Portugal durante el verano caliente fue la ayuda económica condicionada. Pese al interés creado entre los socios europeos por el plan de ayuda alemán a Portugal, solamente Holanda se animó a presentar un programa similar, aunque de mucha menor entidad. De esta forma, en los meses centrales de 1975 en que Portugal entró en una fase de profunda depresión económica agravada con la llegada de cientos de miles de repatriados de las colonias carentes de trabajo y vivienda, el crédito de 70 millones de marcos de la RFA aparecía como uno de los pocos recursos a mano para reanimar el sistema productivo. ${ }^{135}$ Consciente de las expectativas que el crédito despertaba, la RFA decidió sacarle

\footnotetext{
130 João FIGUEIRA, “Caso República. A morte de um jornal cansado de lutar”, en: Maria INÁCIA REZOLA, Pedro MARQUES GOMES (coord.), Lisboa, Tinta da China, 2014, pp. 79-111.

${ }^{131}$ Véase el testimonio del reportero de la televisión alemana Arno Münster, en el diario O Século, 22.7.1975.

132 MÓNICA FONSECA, “É Preciso Regar os Cravos!”, pp. 261 y ss.

133 "Soares en Frankfurt", Portugal Nachrichten, 18.9.1975.

${ }^{134}$ Informe de Elke Sabiel sobre la visita de Mario Soares a la RFA, 25.9.1974, AdsD, FES Hausakten 2972.

135 “¿Por qué dinero para Portugal?”, SPD Pressedienst, 20.6.1975.
} 
el máximo provecho político. Una vez anunciado el plan de ayuda durante la campaña electoral de abril, Bonn no se dio ninguna prisa en implementarlo. El gobierno alemán tenía el máximo interés en que tanto la opinión pública portuguesa como sus dirigentes comprendieran que la ayuda no fluiría si se pretendía utilizarla para consolidar los pilares de un sistema socialista. Este sería el tenor de la conversación entre Helmut Schmidt y Vasco Gonçalves durante la cumbre de la OTAN a finales de mayo. Con su conocido estilo directo, el canciller de la RFA advirtió al primer ministro de Portugal de que su país no podía salir del relativo subdesarrollo sin financiación internacional e inversiones extranjeras. El respaldo externo a la economía portuguesa no llegaría sin embargo mientras Lisboa no devolviera la confianza a los mercados, seriamente dañada con las nacionalizaciones y la proliferación de comités de trabajadores que estaban provocando la caída en picado de la productividad. ${ }^{136}$ En las semanas siguientes, se iniciaron las negociaciones para la ayuda económica alemana a Portugal, mientras la CEE acordó a propuesta de Bonn un crédito a Lisboa. Con la dimisión de los ministros del PS en julio, la RFA suspendió las negociaciones y el Consejo Europeo advirtió que sólo concedería el crédito si en Portugal triunfaba una democracia pluralista. ${ }^{137}$

Durante el mes de agosto de 1975, la presión combinada de las violentas movilizaciones anticomunistas al norte del Tajo, de los partidos a la derecha del PCP que se negaron a formar parte de un nuevo gobierno de Vasco Gonçalves, del sector moderado del MFA liderado por Melo Antunes que en el conocido como documento de los Nueve reclamaban el fin de la deriva comunista, y de los países occidentales que amenazaban con cortar toda ayuda económica, provocaron el aislamiento definitivo del primer ministro, quien presentó su dimisión a comienzos de septiembre. Se abrió así el camino a la definitiva victoria de los sectores moderados y en la emergencia del PS como el partido hegemónico del sistema político portugués que habría de llevar el peso del proyecto de construcción de una democracia europea.

\section{CONCLUSIONES}

Al contrario de cuanto sostenía su propaganda, el Estado Novo nunca estuvo "orgullosamente solo" en el combate por mantener su Imperio y su sistema político autoritario. El principal aliado del Portugal dictatorial fue la potencia emergente en la Europa de postguerra, la RFA. La estrecha cooperación militar con Salazar y Caetano fue vista por la clase política en Bonn, de derecha y de izquierda, como un deber con la defensa del bloque occidental a cuyo destino estaba ligado el propio futuro de Alemania, y como un imperativo económico que obligaba a una permanente expansión de mercados para su industria. Una vez en el poder, los socialdemócratas no necesitaron vencer grandes obstáculos morales para continuar la política de amistad con el régimen luso iniciada por Konrad Adenauer. Confiados en las virtudes de la modernización, Willy Brandt y sus compañeros entendían que cuantos más lazos se estrechasen entre el Portugal dictatorial y la Europa democrática, más pronto ondearía en Lisboa la bandera de la libertad. Tan arraigado llegó a ser este convencimiento o autoengaño entre los dirigentes del SPD, que prefirieron desentenderse de cualquier relación seria con la oposición democrática, para no dañar las relaciones con el gobierno de Lisboa y no debilitar al sector aperturista del régimen, en el que depositaban sus esperanzas de evolución positiva. Todo quedaba a

\footnotetext{
${ }^{136}$ Informe de la entrevista entre Schmidt y Gonçalves, 30.5.1975, PAAA, B-150-329.

${ }^{137}$ Francisco CASTRO, “A CEE e o PREC”, Penélope, 26 (2002), pp. 123-157.
} 
merced del tiempo y de la inevitabilidad de la apertura. El apoyo del SPD a la ASP no fue político, aunque sí de carácter económico y logístico. A la vista de la muy escasa solidaridad efectiva del resto de partidos socialistas europeos, paradójicamente ese respaldo alemán vehiculado por la Fundación Ebert resultó crucial para la consolidación de una fuerza socialista en Portugal antes de la llegada de la democracia.

Occidente no tuvo una posición común hacia la Revolución de los Claveles que de forma absolutamente inesperada se desató tras la implosión del Estado Novo el 25 de abril de 1974. La respuesta americana estuvo marcada por la convicción de que Portugal caminaba desde ese día inevitablemente hacia un régimen socialista, y defendía medidas drásticas como expulsar al país de la OTAN con el fin de minimizar los daños a nivel global. Muy diferente fue la reacción de los países de la CEE, que nunca dieron por perdido a Portugal para la causa de la democracia liberal e intentaron mediante la cooperación económica y el apoyo a los partidos y a los dirigentes militares moderados debilitar a los sectores radicales de izquierda. Al final, la respuesta europea prevaleció sobre la americana, y su aportación resultó esencial para que la Revolución se resolviese conforme a los intereses de los sectores moderados de Portugal y de todo Occidente. En la forja y el desarrollo de esa respuesta europea, la socialdemocracia alemana tuvo un protagonismo absoluto, destacando sobremanera por su capacidad de contribuir al fortalecimiento del partido de Mario Soares. Tan impresionante fue la "solidaridad" del SPD y con el PS que no parecía lógico que careciese de pasado, y por ello mismo este tuvo que ser inventado. ${ }^{138}$

\footnotetext{
${ }^{138}$ Solo sabemos de un socialdemócrata alemán que se sorprendiera negativamente por esa reinvención del pasado. Se trata de Robert Lamberg, quien había dejado la Fundación Ebert poco después de haber intentado sin éxito que Mario Soares fuese recibido en Bonn por el ministro de Exteriores Willy Brandt. En sus memorias, tras narrar aquella fracasada gestión del verano de 1969 y las palabras elogiosas que Soares le dedicó al proclamarle como el único amigo verdadero que los socialistas portugueses tenían en Alemania, Lamberg escribe: "El episodio tuvo todavía un epílogo absurdo-paradójico. Pocos años más tarde, en marzo de 1975, encontré en Nueva York a Brandt (...). Durante un almuerzo celebrado en su honor por el cónsul general alemán y al que yo estaba invitado, (...) Brandt (...) habló de Soares como su 'viejo y buen amigo'. Lo dijo sin pestañear, y yo sentí, dicho suavemente, un malestar profundo." Robert F. LAMBERG, Bootspartie am Acheron, p. 347.
} 